1 ФГАОУ ВО «Первый Московский государственный медицинский университет им. И.М. Сеченова» Минздрава России (Сеченовский Университет), Москва, Россия

${ }^{2}$ ФГБУ «Национальный медицинский исследовательский центр эндокринологии» Минздрава России, Москва, Россия

Старение - мультифакторный биологический процесс, неизбежно затрагивающий каждого человека. Дегенеративные процессы, начинаясь на клеточном и молекулярном уровнях, постепенно влияют на изменение функциональных возможностей всех органов и систем. Прогероидные синдромы (от греч. progērōs - преждевременно состарившийся), или синдромы преждевременного старения, представляют собой клинически и генетически гетерогенную группу редких наследственных заболеваний, характеризующихся ускоренным старением организма. К прогериям и сегментарным прогероидным синдромам относят свыше десятка заболеваний, однако наиболее ярко признаки преждевременного старения проявляются при синдроме Хатчинсона-Гилфорда (прогерия детского возраста) и синдроме Вернера (прогерия взрослых). В представленном обзоре обобщены последние данные литературы, отражающие этиологию и клиническую картину прогерий и сегментарных прогероидных синдромов человека. На примере прогероидных синдромов рассмотрены молекулярные механизмы старения в целом. Обсуждаются современные возможности и потенциальные пути влияния на механизмы развития возрастных изменений. Дальнейшее изучение генетических причин, а также разработка методов лечения прогерий и сегментарных прогероидных синдромов может быть перспективным направлением для коррекции возрастных изменений человека и увеличения продолжительности жизни.

КЛЮЧЕВЫЕ СЛОВА: преждевременное старение; прогерия; синдром Хатчинсона-Гилфорда; синдром Вернера; ламинопатии; теломеры; лонафарниб

\title{
HEREDITARY SYNDROMES WITH SIGNS OF PREMATURE AGING
}

\section{(c) Olga O. Golounina' ${ }^{1}$ Valentin V. Fadeev'1' Zhanna E. Belaya ${ }^{2}$}

${ }^{1}$ I.M. Sechenov First Moscow State Medical University of the Ministry of Health of the Russian Federation (Sechenov University), Moscow, Russia

${ }^{2}$ Endocrinology Research Centre, Moscow, Russia

Aging is a multi-factor biological process that inevitably affects everyone. Degenerative processes, starting at the cellular and molecular levels, gradually influence the change in the functional capabilities of all organs and systems. Progeroid syndromes (from Greek. progērōs - prematurely old), or premature aging syndromes, represent clinically and genetically heterogeneous group of rare hereditary diseases characterized by accelerated aging of the body. Progeria and segmental progeroid syndromes include more than a dozen diseases, but the most clear signs of premature aging are evident in Hutchinson-Guilford Progeria Syndrome and Werner Syndrome. This review summarizes the latest scientific data reflecting the etiology and clinical picture of progeria and segmental progeroid syndromes in humans. Molecular mechanisms of aging are considered, using the example of progeroid syndromes. Modern possibilities and potential ways of influencing the mechanisms of the development of age-related changes are discussed. Further study of genetic causes, as well as the development of treatment for progeria and segmental progeroid syndromes, may be a promising direction for correcting age-related changes and increasing life expectancy.

KEYWORDS: Premature aging; progeria; Hutchinson-Guilford Progeria Syndrome;Werner Syndrome; laminopathies; telomeres; Lonafarnib

\section{ВВЕДЕНИЕ}

Старение - универсальный и закономерный биологический процесс, характеризующийся снижением компенсаторных возможностей организма. Определенную роль в биологическом старении клеток играют генетические и эпигенетические механизмы, такие как метилирование ДНК, посттрансляционные модификации гистонов H2A, H2B, Н3 и Н4, обеспечивающие укладку ДНК в ядре и являющиеся важным механизмом эпигенетической регуляции структуры и функций хроматина. Кроме того, одним из факторов, влияющим на продолжительность жизни клетки, является скорость укорочения теломер концевых участков хромосом [1].

Несмотря на значительное увеличение средней продолжительности жизни, имеется множество факторов, которые могут ускорить физиологический процесс старения, например, экологические факторы, образ жизни и другие. Однако существуют генетически обусловленные формы преждевременного старения (прогерии), при которых скорость патологических изменений, характерных для старения, увеличена во много раз (таблица 1). 
Таблица 1. Прогерии и сегментарные прогероидные синдромы человека

\begin{tabular}{|c|c|c|c|c|c|}
\hline Заболевание & OMIM & Локус & Ген & Тип наследования & $\begin{array}{c}\text { Генетические } \\
\text { нарушения в клетке }\end{array}$ \\
\hline \multicolumn{6}{|c|}{ Неонатальный прогероидный синдром } \\
\hline $\begin{array}{l}\text { Синдром } \\
\text { Видемана- } \\
\text { Раутенштрауха }\end{array}$ & 264090 & $10 q 22.3$ & POLR3A & Аутосомно-рецессивный & $\begin{array}{c}\text { Нарушения } \\
\text { биосинтеза белков } \\
\text { и жизнедеятельности } \\
\text { клеток }\end{array}$ \\
\hline \multicolumn{6}{|c|}{ Прогероидные ламинопатии } \\
\hline $\begin{array}{l}\text { Синдром } \\
\text { Хатчинсона-Гилфорда }\end{array}$ & 176670 & $1 q 22$ & LMNA & $\begin{array}{l}\text { Аутосомно-доминантный } \\
\text { Аутосомно-рецессивный }\end{array}$ & \multirow{4}{*}{$\begin{array}{c}\text { Нестабильность ядерной } \\
\text { оболочки, «спутывание» } \\
\text { гетерохроматина, } \\
\text { нарушение экспрессии } \\
\text { генов вследствие } \\
\text { накопления мутантного } \\
\text { белка прогерина }\end{array}$} \\
\hline $\begin{array}{l}\text { Рестриктивная } \\
\text { дермопатия }\end{array}$ & 275210 & $\frac{1 p 34.2}{1 q 22}$ & $\begin{array}{c}\text { FACE-1 / } \\
\text { ZMPSTE24 } \\
\text { LMNA }\end{array}$ & Аутосомно-рецессивный & \\
\hline $\begin{array}{l}\text { Мандибулоакральная } \\
\text { дисплазия с } \\
\text { липодистрофией типа А }\end{array}$ & 248370 & $1 q 22$ & LMNA & Аутосомно-рецессивный & \\
\hline $\begin{array}{l}\text { Мандибулоакральная } \\
\text { дисплазия с } \\
\text { липодистрофией типа В }\end{array}$ & 608612 & $1 p 34.2$ & $\begin{array}{c}\text { FACE-1 / } \\
\text { ZMPSTE24 }\end{array}$ & Аутосомно-рецессивный & \\
\hline \multicolumn{6}{|c|}{ RecQ-ассоциированные прогероидные синдромы } \\
\hline Синдром Вернера & 277700 & $8 p 12$ & WRN & Аутосомно-рецессивный & $\begin{array}{c}\text { Ускоренное укорочение } \\
\text { теломер, геномная } \\
\text { и хромосомная } \\
\text { нестабильность }\end{array}$ \\
\hline Синдром Блума & 210900 & $15 q 26.1$ & $B L M$ & Аутосомно-рецессивный & Хромосомные аберрации \\
\hline $\begin{array}{l}\text { Синдром } \\
\text { Ротмунда-Томсона }\end{array}$ & 268400 & $8 q 24.3$ & RECQL4 & Аутосомно-рецессивный & $\begin{array}{l}\text { Хромосомная } \\
\text { нестабильность }\end{array}$ \\
\hline \multicolumn{6}{|c|}{ Сегментарные прогероидные синдромы, связанные с нарушением репарации ДНК } \\
\hline \multirow{9}{*}{$\begin{array}{l}\text { Пигментная } \\
\text { ксеродерма }\end{array}$} & 278700 & $9 q 22.33$ & $X P A$ & \multirow{9}{*}{ Аутосомно-рецессивный } & \multirow{9}{*}{$\begin{array}{c}\text { УФ-индуцированное } \\
\text { повреждение ДНК } \\
\text { и гибель клеток, } \\
\text { накопление онкогенных } \\
\text { мутаций, высокий риск } \\
\text { малигнизации }\end{array}$} \\
\hline & 610651 & $2 q 14.3$ & $X P B / E R C C 3$ & & \\
\hline & 278720 & $3 p 25.1$ & $X P C$ & & \\
\hline & 278740 & $11 \mathrm{p} 11.2$ & $D D B 2$ & & \\
\hline & 278730 & $19 q 13.32$ & $E R C C 2$ & & \\
\hline & 278760 & $16 p 13.12$ & ERCC4 & & \\
\hline & 278780 & $13 q 13.1$ & ERCC5 & & \\
\hline & 278750 & $6 p 21.1$ & POLH & & \\
\hline & 278720 & $11 q 13.5$ & UVRAG & & \\
\hline \multirow{4}{*}{ Синдром Коккейна } & 126340 & $19 q 13.32$ & ERCC2 & \multirow{4}{*}{ Аутосомно-рецессивный } & \multirow{11}{*}{$\begin{array}{c}\text { УФ-индуцированное } \\
\text { повреждение ДНК } \\
\text { и гибель клеток }\end{array}$} \\
\hline & 133530 & $13 q 33.1$ & ERCC5 & & \\
\hline & 133540 & $10 q 11.23$ & ERCC6 & & \\
\hline & 216400 & $5 q 12.1$ & ERCC8 & & \\
\hline \multirow{7}{*}{ Трихотиодистрофия } & 601675 & $19 q 13.32$ & $E R C C 2$ & \multirow{2}{*}{ - Аутосомно-рецессивный } & \\
\hline & 616390 & $2 q 14.3$ & $X P B / E R C C 3$ & & \\
\hline & 616395 & $6 q 25.3$ & GTF2H5 & Неизвестно & \\
\hline & 234050 & $7 p 14.1$ & MPLKIP & Аутосомно-рецессивный & \\
\hline & 300953 & $X q 24$ & RNF113A & Х-сцепленный доминантный & \\
\hline & 616943 & $8 p 12$ & GTF2E2 & Аутосомно-рецессивный & \\
\hline & 618546 & $5 p 13.3$ & TARS1 & Аутосомно-рецессивный & \\
\hline
\end{tabular}


Таблица 1. Прогерии и сегментарные прогероидные синдромы человека (окончание)

\begin{tabular}{|c|c|c|c|c|c|}
\hline Заболевание & OMIM & Локус & Ген & Тип наследования & $\begin{array}{c}\text { Генетические } \\
\text { нарушения в клетке }\end{array}$ \\
\hline \multicolumn{6}{|c|}{ Другие наследственные заболевания с признаками преждевременного старения } \\
\hline \multirow{9}{*}{ Синдром Секкеля } & 210600 & $3 q 23$ & ATR & \multirow{9}{*}{ Аутосомно-рецессивный } & \multirow{9}{*}{$\begin{array}{c}\text { Нарушение регуляции } \\
\text { клеточного цикла, } \\
\text { хромосомная } \\
\text { нестабильность }\end{array}$} \\
\hline & 606744 & $18 q 11.2$ & RBBP8 & & \\
\hline & 613676 & $13 q 12.12-q 12.13$ & CENPJ & & \\
\hline & 613823 & $15 q 21.1$ & CEP152 & & \\
\hline & 614728 & $3 q 22.2$ & CEP63 & & \\
\hline & 614851 & $14 q 22.1$ & NIN & & \\
\hline & 615807 & $10 q 21.3$ & DNA2 & & \\
\hline & 616777 & $3 p 21.31$ & TRAIP & & \\
\hline & 617253 & $8 q 24.13$ & NSMCE2 & & \\
\hline \multirow{10}{*}{$\begin{array}{l}\text { Врожденный } \\
\text { дискератоз }\end{array}$} & 127550 & $3 q 26.2$ & TERC & \multirow{6}{*}{ - Аутосомно-рецессивный } & \multirow{10}{*}{$\begin{array}{c}\text { Ускоренное укорочение } \\
\text { теломер, хромосомная } \\
\text { нестабильность, } \\
\text { неконтролируемое } \\
\text { деление клеток, } \\
\text { истощение пула } \\
\text { стволовых клеток }\end{array}$} \\
\hline & 613990 & $14 q 12$ & TINF2 & & \\
\hline & 224230 & $15 q 14$ & NOLA3 & & \\
\hline & 613987 & $5 q 35.3$ & NOLA2 & & \\
\hline & 613988 & $17 p 13.1$ & WRAP53 & & \\
\hline & 616353 & $16 p 13.12$ & PARN & & \\
\hline & 613989 & $5 p 15.33$ & TERT & \multirow{3}{*}{$\begin{array}{l}\text {-Аутосомно-доминантный } \\
\text { Аутосомно-рецессивный }\end{array}$} & \\
\hline & 615190 & $20 q 13.33$ & RTEL 1 & & \\
\hline & 616553 & $16 q 22.1$ & $A C D$ & & \\
\hline & 305000 & $\mathrm{Xq} 28$ & $D K C 1$ & Х-сцепленный рецессивный & \\
\hline
\end{tabular}

Наиболее ярко признаки преждевременного старения проявляются при синдроме Хатчинсона-Гилфорда (прогерия детского возраста) и синдроме Вернера (прогерия взрослых) [2].

Первые данные о редких в человеческой популяции случаях синдромов преждевременного старения были опубликованы еще на рубеже XIX-XX вв. [3-5]. На сегодняшний день созданы различные экспериментальные модели, позволяющие лучше понять клеточную и молекулярную основы клинически гетерогенных редких генетических нарушений и разработать потенциальное лечение прогероидных синдромов, что может заложить начало терапии возраст-ассоциированных заболеваний.

В настоящем обзоре литературы суммируются существующие данные о прогероидных синдромах, клинических проявлениях, механизмах их развития и потенциальных путях влияния на возраст-ассоциированные нарушения.

\section{НЕОНАТАЛЬНЫЙ ПРОГЕРОИДНЫЙ СИНДРОМ}

Синдром Видемана-Раутенштрауха (ОМIM \# 264090) был впервые описан T. Rautenstrauch (1977 г.) [6] и H.R. Wiedemann (1979 г.) [7]. Заболевание наследуется по аутосомно-рецессивному типу и, как предполагается, обусловлено биаллельными патогенными вариантами в гене POLR3A, кодирующем субъединицу PHК-полимеразы III $[8,9]$. К 2017 г. в литературе представлен 51 случай данного заболевания, однако только у 15 пациентов диагноз счи- тается полностью подтвержденным [10]. Характерными фенотипическими особенностями данного заболевания являются выраженная задержка роста в антенатальном и постнатальном периодах, низкая масса тела при рождении, псевдогидроцефалия, генерализованная липодистрофия, сухая морщинистая кожа, выраженные вены на голове, треугольное лицо с клювовидным носом и глубоко посаженными глазами. По мере взросления ребенка внешний вид его не изменяется [10, 11]. Помимо основных признаков синдрома, нередко наблюдаются дислипидемия, гиперпролактинемия, гипотиреоз, различные скелетные аномалии - врожденная дисплазия бедра, длинные (марфаноподобные) пальцы, чрезмерные суставные контрактуры, ригидность и слабость в суставах, прогрессирующий кифосколиоз, отставание костного возраста от паспортного [12]. Средняя продолжительность жизни больных составляет 6 лет.

\section{ПРОГЕРОИДНЫЕ ЛАМИНОПАТИИ}

Ламинопатии, обусловленные мутациями в гене ламина A/C (LMNA), являются причиной более полутора десятка заболеваний и клинических синдромов, таких как мышечная дистрофия Эмери-Дрейфуса, дилатационная кардиомиопатия с нарушением атриовентрикулярной проводимости, синдром Малуфа, семейные липодистрофии, болезнь Шарко-Мари-Тута и других. Прогероидные ламинопатии представляют собой синдромы, характеризующиеся преждевременным старением, и включают 
синдром Хатчинсона-Гилфорда, мандибулоакральную дисплазию с липодистрофией типа $A$ и типа $B$, рестриктивную дермопатию [13, 14].

Синдром Хатчинсона-Гилфорда (ОМIM \# 176670) это редкое генетическое заболевание, обусловленное мутациями в гене LMNA (1q22), кодирующем ламин A/C [15]. Почти в 90\% всех выявленных случаев прогерии Хатчинсона-Гилфорда обнаруживаются мутации de novo в экзоне 11 гена LMNA (c.1824C>T, p.G608G; c.1822G>A, p.G608S), приводящие к синтезу аномального белка, укороченного на 50 аминокислотных остатков, вблизи карбокситерминального домена преламина A [16].

Известно, что ламин - один из структурных белков ядерной ламины, основная функция которого - поддержание формы и размеров клеточного ядра посредством формирования комплексов с белками ядерной мембраны и цитоплазматическими структурами [17]. Ламины A и С образуются из преламина А (прогерина) в результате альтернативного сплайсинга по десятому экзону и процессинга его С-концевой области. Нарушения превращения преламина А в зрелый ламин сопровождаются накоплением прогерина в нуклеоплазме ядра, что обуславливает нестабильность ядерной оболочки, «спутывание» гетерохроматина, приводя к нарушению экспрессии генов [18]. Заболевание впервые было описано английским врачом Джонатаном Хатчинсоном (Jonathan Hutchinson) в 1886 г. у шестилетнего мальчика с атрофией кожи и ее придатков [3]. В дальнейшем его соотечественник Гастингс Гилфорд (Hastings Gilford) изучил клинико-морфологические особенности данного заболевания и ввел термин «прогерия» [4].

Согласно оценочным данным, распространенность синдрома Хатчинсона-Гилфорда составляет 1 случай на 4000 000-8 000000 новорожденных [19]. Клинические признаки заболевания обычно проявляются на 1-2 году жизни ребенка и характеризуются низкорослостью, низкой массой тела, уменьшенной лицевой частью черепа, микрогнатией, липодистрофией, генерализованной остеодисплазией с остеолизом и патологическими переломами (табл. 2), алопецией и преждевременным старением $[20,21]$. Средняя продолжительность жизни больных составляет 13 лет (от 7 до 27). Сердечно-сосудистые заболевания занимают лидирующую позицию в структуре причин смертности у данных пациентов [22].

Одним из примеров сегментарных прогероидныхсиндромов, вызванных мутациями в гене FACE-1/ZMPSTE24 (1 p34), кодирующем металлопротеазу, участвующую в посттрансляционных модификациях ламина А/C в зрелый ламин, является рестриктивная дермопатия (OMIM \# 275210) - крайне редкое летальное заболевание с аутосомно-рецессивным типом наследования [23]. Подобно прогерии Хатчинсона-Гилфорда, происходит накопление мутантного белка прогерина, но в большей степени. Сниженная фетальная подвижность, задержка внутриутробного развития плода служат первыми признаками данного заболевания. Новорожденные с рестриктивной

Таблица 2. Основные фенотипы прогероидных ламинопатий с преимущественным поражением костей и суставов

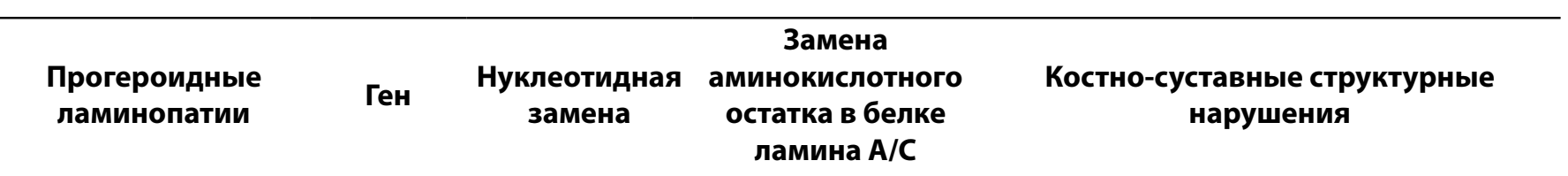

Синдром

Хатчинсона-

Гилфорда

LMNA

c.C1824T

p.Gly608Gly

Отсроченное сращение черепных швов, генерализованная остеодисплазия, остеолиз нижней челюсти, ключицы и фаланг пальцев верхних и нижних конечностей, остеопороз, патологические переломы

\begin{tabular}{lcc}
\hline & \multicolumn{1}{l}{ LMNA } & \\
\cline { 2 - 2 } $\begin{array}{l}\text { Рестриктивная } \\
\text { дермопатия }\end{array}$ & $\begin{array}{l}\text { FACE-1/ } \\
\text { ZMPSTE24 }\end{array}$ &
\end{tabular}

Множественные контрактуры суставов верхних и нижних конечностей, остеолиз ключицы, деминерализация костей, кифосколиоз

Мандибулоакральная

дисплазия с липодистрофией $\begin{array}{lll}\text { LMNA } & \text { c.1580G }>\mathrm{A} \quad \text { p.Arg527His }\end{array}$ типа A

C.1580G $>$ A p.Arg527His

Мандибулоакральная

дисплазия с липодистрофией типа B

$\begin{array}{cc}\text { FACE-1 / } & \text { c.1085dupT } \\ \text { ZMPSTE24 } & \text { c.794A }>\text { G }\end{array}$

p.Phe361fsX379

p.Asn265Ser
Отсроченное сращение черепных швов, остеолиз нижней челюсти, ключицы и фаланг пальцев, кальциноз кожи и мягких тканей, фиброзная дисплазия, остеопороз, замедленная консолидация переломов

Отсроченное сращение черепных швов, остеолиз нижней челюсти, ключицы и фаланг пальцев, деминерализация скелета, тяжелый остеопороз,

множественные патологические переломы, замедленная консолидация переломов

\begin{tabular}{|c|c|c|c|c|}
\hline \multirow{2}{*}{$\begin{array}{l}\text { Атипичный синдром } \\
\text { Вернера }\end{array}$} & LMNA & \multirow{2}{*}{ c.584G $>C$} & \multirow{2}{*}{ p.Ala57Pro } & \multirow{2}{*}{ Арахнодактилия, сколиоз, остеопороз } \\
\hline & RECQL2 & & & \\
\hline
\end{tabular}


дермопатией имеют характерный внешний вид - тонкую, багрового цвета кожу, с просвечивающими через нее сосудами, маленький острый нос, О-образный рот, деформированные, низко посаженные уши, множественные контрактуры суставов верхних и нижних конечностей. Большинство детей рождаются мертвыми либо умирают в первые дни жизни от респираторной дыхательной недостаточности [24].

Наряду с синдромом Хатчинсона-Гилфорда и рестриктивной дермопатией, к прогероидным ламинопатиям относят мандибулоакральную дисплазию с липодистрофией типа А (ОМІМ \# 248370), обусловленную мутациями в гене LMNA [25], и мандибулоакральную дисплазию с липодистрофией типа В (ОМIM \# 608612), связанную с мутациями в гене FACE-1/ZMPSTE24 [26]. Пациенты с мандибулоакральной дисплазией типа А отличаются низким ростом, уменьшением периферической подкожно-жировой клетчатки и увеличением жировой ткани в области лица, шеи и туловища, имеют некоторые признаки, напоминающие прогерию Хатчинсона-Гилфорда: «птичье лицо», атрофию кожи, дисплазию ногтевых фаланг, алопецию. В свою очередь, мандибулоакральная дисплазия типа В характеризуется генерализованной липодистрофией (липоатрофией) и быстро прогрессирующей гломерулонефропатией. Различные метаболические нарушения, такие как инсулинорезистентность, сахарный диабет, гиперлипидемия, скелетные аномалии, пигментация кожи, встречаются в обоих вариантах [27].

\section{RECQ-АССОЦИИРОВАННЫЕ ПРОГЕРОИДНЫЕ СИНДРОМЫ}

RecQ-хеликазы представляют собой семейство ферментов, играющих важную роль в поддержании стабильности клеточного генома и репарации ДНК. Существуют 5 генов RecQ человека: RECQL 1, BLM, WRN, RECQL4, RECQL5 [28], из которых 3 связаны с развитием наследственных заболеваний - синдром Вернера (ген WRN) [29], синдром Блума (BLM) [30], синдром Ротмунда-Томсона (RECQL4) [31].

Прогерия взрослых - синдром Вернера (OMIM \# 277700) был впервые описан немецким студентоммедиком Отто Вернером (Otto Werner) в 1904 г. Он наблюдал четырех братьев и сестер в возрасте от 31 до 40 лет с сочетанием низкорослости, катаракты, склеродермии и ранним поседением волос [5]. В основе заболевания лежит мутация в гене WRN (8p12), кодирующем одноименный белок WRN, представляющий собой хеликазу из семейства RecQ [29]. Одним из основных признаков синдрома Вернера является нестабильность клеточного генома, что свидетельствует об участии WRN-хеликазы в поддержании целостности ядерной ДНК. Кроме того, WRN совместно с белками TRF1, TRF2, РОT1, TIN2, TPP1 и RAP1, составляющими комплекс, называемый шелтерином, способствуют поддержанию длины теломер [32].

Теломеры представляют собой концевые участки хромосом, образованные специфической теломерной ДНК и белками, защищающими концы хромосом от деградации и систем репарации двухцепочечных разрывов. Теломеры человека и всех позвоночных представлены в виде монотонного повтора TTAGGG и 3'-выступающего участка G-цепи длиной 150-200 нуклеотидов, способного переплетаться с двухцепочечным участком теломеры, образуя T-петли и D-петли [33]. Четыре теломерных повтора могут образовывать G-квадруплексные структуры, вызывающие укорачивание теломер в клетках. При этом нарушается взаимодействие шелтеринового комплекса с теломерной ДНК, утрачивается стабильность теломер, что воспринимается клеткой как сигнал повреждения. В результате запускается механизм репликативного старения клеток $[34,35]$. Нормальная экспрессия WRN способствует репликации теломерных участков и поддержанию их длины путем разделения Т-петель, D-петель и G-квадруплексных структур [36].

При синдроме Вернера наблюдаются генетически детерминированная нестабильность хромосом, ускоренное укорочение теломер, нарушения репликации и репарации ДНК и гиперметилирование гистонов, что является факторами, запускающими клеточное старение, приводя к возникновению внешних признаков старости [37-39]. Фибробласты больных синдромом Вернера в 3-5 раз быстрее исчерпывают свой пролиферативный потенциал по сравнению с клетками здоровых доноров и демонстрируют 10-кратное увеличение темпа спонтанных мутаций, а также быстрое укорочение длины теломер [38-40]. Кроме того, клетки с короткими теломерами теряют генетическую стабильность и могут становиться родоначальниками опухолей.

По данным литературы, частота встречаемости синдрома Вернера в разных странах мира составляет 1 случай на 1000 000-10000 000 новорожденных, однако наибольшая распространенность отмечается в Японии 1:100 000 [32, 41]. На сегодняшний день описано более 80 различных мутаций гена $W R N$, большинство из которых $(65,28 \%)$ являются точечными миссенс-мутациями [42].

Заболевание наследуется по аутосомно-рецессивному типу, манифестирует в возрасте 15-30 лет. Первый характерный признак - отсутствие пубертатного скачка роста и относительно низкий рост по сравнению со средней нормой для взрослого человека. Маскообразное лицо, клювовидный нос и выступающий подбородок отличают больных с синдромом Вернера. На третьем десятке жизни отмечается появление седых волос, связанное с ускоренным старением меланобластов, алопеция, развиваются катаракта и гипогонадизм. Постепенное истончение кожи и атрофия подкожной жировой клетчатки приводят к развитию склеродермии $[43,44]$.

Заболевание характеризуется физическими и метаболическими нарушениями, сопровождающимися тяжелыми возрастными осложнениями, такими как сахарный диабет, артериальная гипертензия, сердечно-сосудистые заболевания, которые обычно наблюдаются у пожилых людей [45]. Различные нарушения костного метаболизма, нарушения фосфорно-кальциевого обмена, проявляющиеся метастатической кальцификацией мягких тканей, являются еще одним характерным проявлением синдрома Вернера. Рентгенологически кальцификация мягких тканей обнаруживается у $80 \%$ пациентов, прежде всего в ахилловом сухожилии. Помимо этого, наиболее частыми зонами локализации кальцификатов являются коленный, локтевой и голеностопный суставы, периартикулярные ткани. Описаны случаи обширной кальцификации мягких тканей, сопровождающиеся изъязвлениями кожи и выраженным болевым синдромом вследствие спонтанного вскрытия кальцинозных очагов [46-48]. 
Прогрессирующая и генерализованная потеря мышечной массы, наиболее выраженная в конечностях и развивающаяся в среднем к 40 годам, характерна для 90\% пациентов с синдромом Вернера $[49,50]$. Известно, что популяция клеток-предшественников, представленная в скелетной мускулатуре, происходит от недифференцированных мезенхимальных стволовых клеток (МСK) костного мозга. В исследовании Zhang W. и соавт. [39] было показано, что MCK, лишенные белка WRN, демонстрировали характерные черты ускоренного клеточного старения, включая низкий пролиферативный потенциал, повышенную активность ассоциированной со старением $\beta$-галактозидазы (SA- $\beta$-gal) и accoциированного со старением секреторного фенотипа (senescence associated secretory phenotype, SASP). Последующая трансплантация MCK в мышцу мышей значительно сокращала продолжительность их жизни по сравнению со здоровым контролем. Накопление стареющих клеток и высокая секреция SASP, способствовавшая распространению преждевременного старения на соседние клетки, приводили к нарушениям функционирования тканей, ускоренному старению особей и различным возраст-ассоциированным заболеваниям. Кроме того, факторы SASP, секретируемые стареющими MCK, ускоряли миграцию и пролиферацию трансформированных клеток, тем самым способствуя опухолевой прогрессии.

Риск развития злокачественных новообразований (3НО) при синдроме Вернера в 54 раза выше по сравнению с общей популяцией [51]. До 50\% зарегистрированных 3 НО составляют саркомы мягких тканей - рабдомиосаркома, злокачественная фибринозная гистиоцитома, лейомиосаркома и саркомы верхних конечностей. Имеются сообщения о развитии у больных синдромом Вернера фолликулярного рака щитовидной железы, меланомы и менингиомы [49]. Большинство пациентов не доживают до возраста 50 лет, смертность наступает от $3 \mathrm{HO}$ и инфаркта миокарда [44].

Синдром Блума, также известный как синдром Блума-Торре-Махачека, врожденная телеангиэктатическая эритема (ОМІМ \# 210900), - редкий аутосомно-рецессивный сегментарный прогероидный синдром, отличительными особенностями которого являются выраженная геномная нестабильность, проявляющаяся ускоренным накоплением различных мутаций в соматических клетках, иммунодефицит, высокая предрасположенность к злокачественным новообразованиям в молодом возрасте (до 30 лет) [52]. Синдром был впервые описан американским дерматологом Дэвидом Блумом (Dr. David Bloom) в 1954 г. [53].

Заболевание обусловлено мутациями в гене BLM (15q26.1), кодирующем ДНК-хеликазу RecQl3, играющую важную роль в поддержании целостности генома [30]. Наиболее часто синдром Блума встречается среди евреев-ашкенази (1 случай на 48000 новорожденных [54]), что связано с наличием аллеля c.2207_2212delATCTGAinsTAGATTC-BLMAsh в этой группе населения [55].

Характерные фенотипические особенности данного заболевания - низкорослость (рост взрослых пациентов редко превышает 150 см), длинное и узкое лицо с непропорционально большими ушами и носом, изменения пигментации кожи, включая появление гипо- и гиперпигментированных пятен и родинок. На лице под воздействием солнечных лучей развивается характерная телеангиэктазия в форме «бабочки». Синдром Блума, в отличие от синдрома Вернера, не ассоциирован с преждевременным старением и ранним развитием таких заболеваний, как сахарный диабет, остеопороз, атеросклероз. В то же время большинство больных редко доживают до 50 лет [56].

Еще одним примером RecQ-ассоциированных сегментарных прогероидных синдромов является синдром Ротмунда-Томсона (ОМІМ \# 268400), известный как врожденная пойкилодермия [57]. Первое описание данного синдрома принадлежит немецкому офтальмологу August von Rothmund (1868 г.), наблюдавшему ребенка с сочетанием двусторонней катаракты и своеобразным поражением кожи (дисхромия, телеангиэктазии). Позднее британский дерматолог M.S. Thomson в 1923 г. описал «до настоящего времени неописанную наследственную болезнь» и ввел термин «врожденная пойкилодермия (англ. poikilodermia congenita)» [58]. К 2019 г. в литературе описано около 400 случаев данного заболевания [59].

Синдром Ротмунда-Томсона представляет собой редкий наследственный симптомокомплекс, обусловленный мутациями гена RECQL4 (8q24.3) семейства RecQ-хеликаз и имеющий некоторые симптомы преждевременного старения, сходные с синдромом Вернера [31, 60]. Первые признаки заболевания проявляются к 3-6 месяцу жизни ребенка. Эритематозные пятна, особенно выраженные на лице, шее, ушных раковинах, ягодицах, дорсальных поверхностях кистей и стоп, постепенно подвергаются обратному развитию, формируя участки сетчатой гиперпигментации и депигментации с телеангиэктазиями (пойкилодермия), развиваются атрофические полосы, расширяются сосуды. Примерно у половины больных в возрасте 4-7 лет формируется двусторонняя катаракта, почти всегда приводящая к слепоте [61]. К другим проявлениям заболевания относятся низкорослость, различные скелетные аномалии, гипогонадизм, гиперпаратиреоз, предрасположенность к 3НО, особенно к остеосаркоме (32\% случаев).

\section{СЕГМЕНТАРНЫЕ ПРОГЕРОИДНЫЕ СИНДРОМЫ, ОБУСЛОВЛЕННЫЕ ДЕФЕКТАМИ ЭКСЦИЗИОННОЙ РЕПАРАЦИИ НУКЛЕОТИДОВ}

Существуют системы генетической репарации, при действии которых поврежденные азотистые основания вырезаются из цепи ДНК соответствующими гликозилазами, отсюда происходит и сам термин «эксцизионная репарация» (с англ. ехсіsion - вырезание). Эксцизионная репарация нуклеотидов (nucleotide excision reparation, NER) - один из основных путей защиты клетки от различных повреждений, искажающих спираль ДНК. Мутации некоторых генов, кодирующих белки, участвующие в NER, приводят к развитию трех фенотипически различных наследственных заболеваний человека - пигментной ксеродермы, синдрома Коккейна и трихотиодистрофии [62].

Пигментная ксеродерма - крайне редко встречающееся генетически гетерогенная группа наследственных заболеваний, характеризующихся различными симпто- 
мами поражения кожи, гиперчувствительностью культрафиолетовому излучению, склонностью к малигнизации вследствие нарушения NER [63]. Пигментная ксеродерма обусловлена биаллельными патогенными мутациями в генах XPA (9q22.33), XPB/ERCC3 (2q14.3), XPC (3p25.1), DDB2 (11p11.2), ERCC2 (19q13.32), ERCC4 (16p13.12), ERCC5 (13q13.1), POLH (6p21.1), UVRAG (11q13.5) [64].

Заболевание проявляется в возрасте от 6 месяцев до 14-35 лет. На фоне кратковременного нахождения на солнце в раннем детском возрасте возникают обильные пигментные пятна с неровными краями диаметром до 5 мм, похожие на множественные веснушки. В дальнейшем происходят постепенное истончение кожи с телеангиэктазиями, атрофией, преждевременным старением, пигментными высыпаниями типа лентиго, истончения хрящей носа, ушных раковин, наблюдаются различные поражения глаз, такие как кератоконъюнктивит, блефарит, помутнение роговицы и ее васкуляризация [65]. Прогрессирование заболевания с возрастом сопровождается развитием доброкачественных и злокачественных эпителиальных опухолей кожи (плоскоклеточный рак кожи, базальноклеточный рак кожи, меланома), предраковых состояний и $3 \mathrm{HO}$ слизистой оболочки полости рта (лейкоплакия, актинический хейлит, рак кончика языка и губ), опухолей центральной нервной системы (медуллобластома, глиобластома, астроцитома спинного мозга, шваннома) и внутренних органов [66-69]. Неврологическая симптоматика, проявляющаяся слабоумием, нейросенсорной тугоухостью, атаксией, гипо- и арефлексией, периферической нейропатией, встречается у $24 \%$ больных с возраста двух лет [66].

Раннее развитие и тяжелое течение опухолевого процесса, быстрый рост и метастазирование $3 \mathrm{HO}$ обуславливают высокую летальность больных пигментной ксеродермой в молодом возрасте. Несмотря на своевременную постановку диагноза, до 50\% пациентов не доживают до 40-летнего возраста $[66,69]$.

Синдром Коккейна, также именуемый синдромом Нилл-Дингуолл (англ. Neill-Dingwall Syndrome), - еще один пример аутосомно-рецессивного генетического заболевания, возникающего вследствие дефектов NER. Синдром был описан английским врачом Эдвардом Альфредом Коккейном (Edward Alfred Cockayne) в 1936 г. [70]. На сегодняшний день известно 5 клинических типов данного заболевания: синдром Коккейна I типа (ОМІМ \# 216400) - классический вариант, обусловленный мутациями гена $\operatorname{ERCC8~(5q12.1);~II~типа~}$ (ОМIM \# 133540) - наиболее распространенная форма заболевания, возникающая вследствие мутаций в гене ERCC6 (10q11.23); III типа (OMIM \# 216411) - крайне редко встречающийся и мало изученный вариант данного синдрома; IV типа (OMIM \# 126340) - мутации гена ERCC2 (19q13.32); V типа (ОМIM \# 133530) вследствие дефектов в гене $E R C C 5$ (13q33.1), кодирующем эндонуклеазу, активно участвующую в процессах репарации ДНК после повреждений, вызванных ультрафиолетовым облучением [71, 72]. Распространенность синдрома Коккейна составляет 1 случай на 2500000 населения [73]. Заболевание, как правило, проявляется на втором году жизни ребенка. Средняя продолжительность жизни больных составляет 20 лет [74].
Пациентов с синдромом Коккейна отличает характерный внешний вид - микроцефалия, клювовидный нос, заостренный подбородок, морщинистая кожа, придающая лицу больного старческое выражение. Прогрессирующая кахексия, низкорослость, нейросенсорная тугоухость, когнитивные нарушения, раннее развитие артериальной гипертензии, нередко приводящей к развитию тяжелых осложнений со стороны сердечно-сосудистой системы (инфаркт миокарда, инсульт, хроническая сердечная и/или почечная недостаточность) являются распространенными проявлениями данного заболевания [74-76]. В отличие от пигментной ксеродермы, также характеризующейся аномальной чувствительностью к ультрафиолетовому излучению, синдром Коккейна не связан с повышенным риском развития 3НО, в том числе новообразований кожи [77].

Помимо пигментной ксеродермы и синдрома Коккейна, к сегментарным прогероидным синдромам, обусловленным нарушением эксцизионной репарации нуклеотидов, относится трихотиодистрофия - крайне редкое и недостаточно изученное наследственное заболевание, представленное широким спектром клинических фенотипов, общим признаком которых являются ломкие волосы с характерным чередованием темных и светлых полос («тигровый хвост»). Клинические проявления трихотиодистрофии могут включать фоточувствительность, ихтиоз, нарушения интеллектуального развития. Описаны случаи атрофии мозжечка, кальцификации базальных ганглиев, микроцефалии, атаксии [77-79]. Большинство пациентов с данным заболеванием имеют мутации в генах системы репарации ДНК - XPD/ERCC2, XPB/ERCC3 или TTDA/GTF2H5 [77].

\section{ДРУГИЕ НАСЛЕДСТВЕННЫЕ ЗАБОЛЕВАНИЯ С ПРИЗНАКАМИ ПРЕЖДЕВРЕМЕННОГО СТАРЕНИЯ}

Синдром Секкеля (птицеголовые карлики, примордиальная карликовость с микроцефалией, Seckel Syndrome) - генетическое заболевание, характеризующееся задержкой внутриутробного развития, низкорослостью в постнатальном периоде, микроцефалией с преждевременным закрытием черепных швов (краниосиностоз), умственной отсталостью и характерными чертами лица с большими глазами, низко посаженными ушами, клювовидным носом с утолщенным кончиком и микрогнатией $[80,81]$.

Описано 9 форм заболевания, связанных с мутациями различных генов: ATR (синдром Секкеля 1; OMIM \# 210600) [82], RBBP8 (синдром Секкеля 2; ОМIM\# 606744) [83], CENPJ (синдром Секкеля 4; OMIM \# 613676) [84], CEP152 (синдром Секкеля 5; ОМIM \# 613823) [85], CEP63 (синдром Секкеля 6; OMIM \# 614728) [86], NIN (синдром Секкеля 7; OMIM \# 614851) [87], DNA2 (синдром Секкеля 8; OMIM \# 615807) [88], TRAIP (синдром Секкеля 9; ОМIM \# 616777) [89], NSMCE2 (синдром Секкеля 10; ОМIM \# 617253) [90]. Частота встречаемости данного синдрома в популяции составляет 1 случай на 10000 [88]. Заболевание нередко сопровождается пороками развития скелета - гипоплазией или отсутствием XII пары ребер, брахидактилией, клинодактилией. У большинства больных отмечаются плоскостопие, кифоз, сколиоз, вывихи локтевых и бедренных суставов, дисплазия головки лучевой кости [81]. 
Врожденный дискератоз, известный как синдром Цинссера-Энгмана-Коула (Zinsser-Engman-Cole Syndrome), - наследственный симптомокомплекс, основными клиническими проявлениями которого являются пойкилодермия, дистрофические изменения ногтей, лейкоплакия слизистой оболочки ротовой полости [91, 92]. Заболевание (англ. Dyskeratosis congenita) впервые описал немецкий дерматолог Ferdinand Zinsser в 1910 г. [93]. Позднее были описаны другие «недерматологические» проявления данного заболевания, вследствие чего врожденный дискератоз определили как мультисистемное заболевание. Распространенность заболевания в среднем составляет 1 случай на 1000 000, соотношение мужчин и женщин - 3:1. В подавляющем большинстве случаев (75\%) тип наследования - аутосомно-рецессивный, сцепленный с Х-хромосомой, гораздо реже (25\%) - аутосомно-доминантный [94].

Гены, обуславливающие развитие врожденного дискератоза (ACD, CTC1, DKC1, NHP2, NOP10, PARN, RTEL1, TERC, TERT, TINF2, WRAP53 и др.), играют важную роль в поддержании длины теломер. Ускоренное укорочение теломер, наблюдаемое при данном заболевании, приводит к слиянию хромосом и, как следствие, нарушению их функционирования и репликации, остановке клеточного цикла и апоптозу клеток [91, 95-97]. Симптомы заболевания развиваются постепенно, манифестируют в возрасте 5-15 лет сетчатой гипер- и гипопигментацией кожи, атрофией кожи, дистрофией ногтей, ладонным гиперкератозом, лейкокератозом слизистых оболочек, слезотечением вследствие атрезии слезных протоков, нарушениями иммунитета. Нередко наблюдаются ум- ственная отсталость, низкорослость, внутричерепные кальцификации, аномалии зубного ряда, некроз головок бедренных костей, остеопороз, гипогонадизм, гипотиреоз [91, 98]. Пациенты с врожденным дискератозом имеют высокий риск развития апластической анемии, нередко расцениваемой педиатрами как анемия Фанкони, миелодиспластического синдрома, острого миелоидного лейкоза, солидных опухолей, фиброза легких, которые в $90 \%$ случаев являются ведущей причиной смертности больных $[99,100]$.

\section{ИЗВЕСТНЫЕ МОЛЕКУЛЯРНЫЕ МЕХАНИЗМЫ СТАРЕНИЯ}

Последние исследования показали, что клеточное старение следует рассматривать как комплекс гетерогенных, но взаимосвязанных механизмов, в которых прямо или опосредованно задействованы продукты генов, дефектных при прогериях, таких как LMNA и WRN.

Известно, что скорость старения во многом зависит от способности клетки отвечать на различные цитотоксические стрессовые воздействия, репарировать ДНК, образовывать и разрушать активные формы кислорода (АФК), а также от пролиферативной активности. По мере старения организма усиливаются процессы перекисного окисления липидов, образования свободных радикалов и АФК, повышается уровень различных маркеров воспаления, что, в конечном итоге, приводит к широкому спектру повреждений ДНК, нарушению эпигенетической регуляции, истощению пролиферативного потенциала клетки, чрезмерному укорочению теломер (рис. 1).

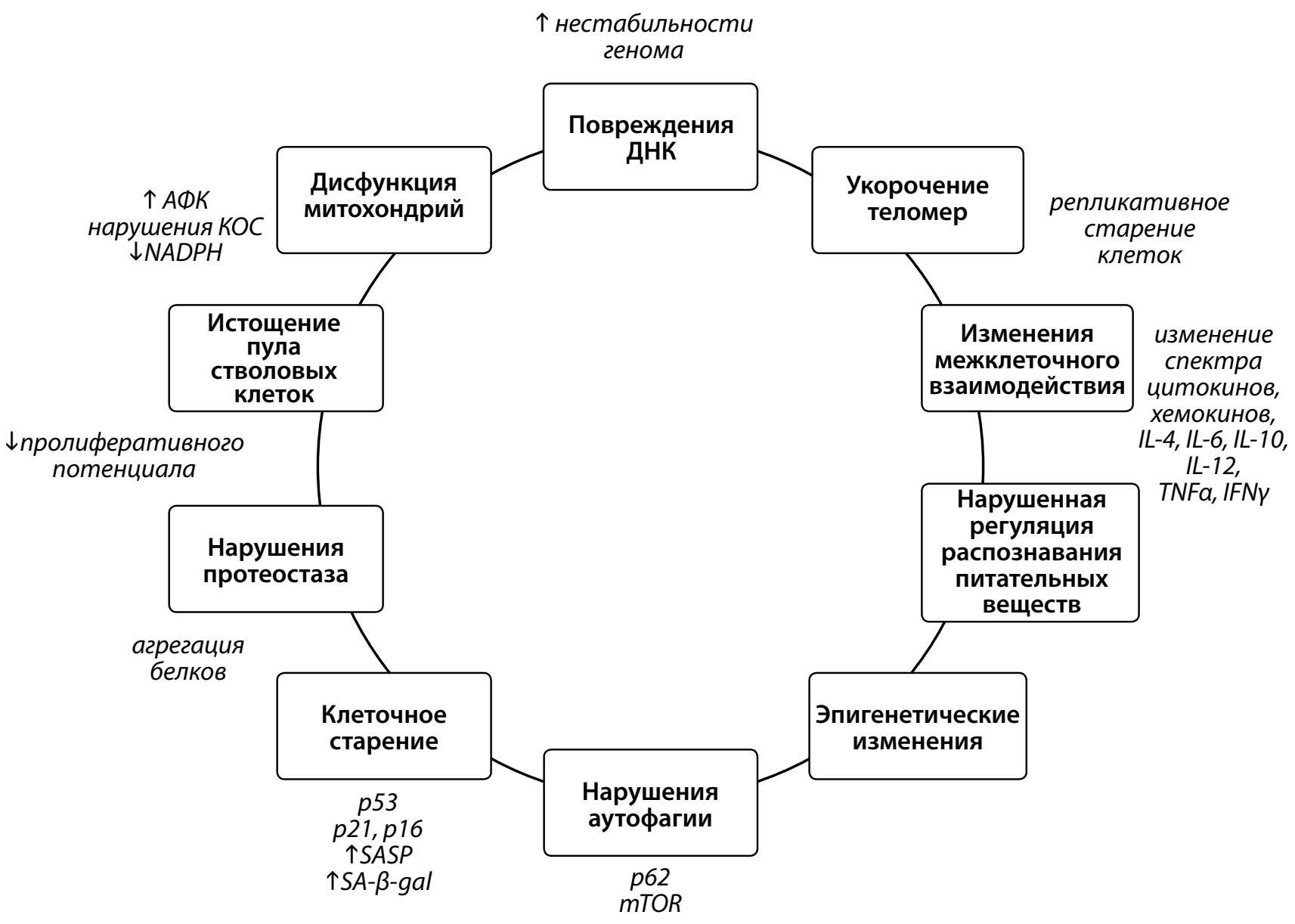

Рис.1. Молекулярные механизмы процесса старения (адаптировано из [158]) 
Доказательства причинно-следственной связи между накоплением генетических повреждений на протяжении всей жизни и старением вытекают из исследований, проведенных на мышах и людях. Неполноценность механизмов репарации ДНК ускоряет старение у мышей [101] и лежит в основе прогероидных синдромов, таких как синдром Хатчинсона-Гилфорда, синдром Вернера, синдром Блума, пигментная ксеродерма, трихотиодистрофия, синдром Коккейна и синдром Секкеля. Примечательно, что при всех этих синдромах наблюдаются профили аберрантного метилирования ДНК (увеличенное метилирование) в гипометилированных областях и, наоборот, потеря метилирования - в гиперметилированных областях, что приводит к увеличению активности ретротранспозона и геномной нестабильности [102]. Потеря гетерохроматина обусловлена также отсутствием WRN при синдроме Вернера [103] и накоплением мутантного белка прогерина - при синдроме ХатчинсонаГилфорда [104].

В последнее время сигнальные каскады RAS/RAF/ MEK/ERK (MAPK) и PI3K/Akt/mTOR все больше привлекают внимание исследователей и клиницистов в качестве перспективной терапевтической мишени, в том числе при синдромах преждевременного старения [14, 105-107]. Существуют доказательства того, что клеточные механизмы и сигнальные пути, регулирующие процесс старения, контролируются протеинкиназой TOR (mammalian target of rapamycin, mTOR) и опухолевым супрессором p53 [108-112]. mTOR представлен относительно большой (290 кДа) серин-треонин киназой, содержащей несколько регуляторных доменов [113]. Белок ITOR регулирует внутриклеточный метаболизм, запуская каскад фосфорилирования белков, а также факторов транскрипции и трансляции. Кроме того, MTOR выступает ключевым компонентом, регулирующим равновесие между ростом и процессом аутофагии в ответ на изменение физиологических условий в клетке или внешний стресс [110]. На сегодняшний день известно множество сигналов, регулирующих mTOR, включая ростовые факторы и уровень аденозинтрифосфата (АТФ) в клетке. При истощении запасов АТФ в клетке повышается уровень аденозинмонофосфата (АМФ) и активируется 5'АМФ-активируемая протеинкиназа (AMP activated protein kinase, AMPK), передавая сигнал об остановке таких энергозатратных процессов, как трансляция и биогенез рибосом, на mTOR, тем самым усиливая катаболические и подавляя анаболические реакции в клетке [114].

B клетках млекопитающих mTOR существует в виде двух белковых комплексов - mTORCl и mTORC2. Большинство исследований сосредоточено на сигнальных путях, контролирующих mTORC1, тогда как функции и регуляции mTORC2 изучены не до конца.

mTORC1 локализуется вблизи митохондрий и играет главную роль в регуляции биосинтеза белка, биогенезе рибосом и механизмах аутофагии [115]. Серия экспериментов на мышах доказала непосредственное участие mTORC1 в индукции аутофагии при окислительном стрессе или дисфункции митохондрий [116].

В свою очередь, mTORC2 обеспечивает организацию цитоскелета, липидный гомеостаз, а также выживание и пролиферацию клеток. Предполагается, что mTORC2 является отрицательным регулятором аутофагии [114].
В нескольких исследованиях было показано, что ингибирование mTORC2 индуцирует процессы аутофагии и атрофии клеток скелетных мышц в условиях голодания, стресса или недостатка факторов роста $[117,118]$.

Роль mTOR в старении и возраст-ассоциированных заболеваниях была продемонстрирована в экспериментах на мышах [119], нематоде Caenorhabditis elegans [120], плодовых мушках Drosophila melanogaster [121], почкующихся дрожжах Saccharomyces cerevisiae [122]. В проведенных исследованиях ингибирование экспрессии mTORC1 антибиотиком рапамицином значительно продлевало жизнь всех организмов.

\section{ПРЕПАРАТЫ, ПОТЕНЦИАЛЬНО ВЛИЯЮЩИЕ НА ПРОЦЕССЫ СТАРЕНИЯ И ПРОДОЛЖИТЕЛЬНОСТЬ ЖИЗНИ}

\section{Рапамицин}

История открытия рапамицина связана с именем канадского биохимика Сурена Сегала (Suren Sehgal), выделившего из обнаруженной им почвенной бактерии Streptomyces higroscopicus сильнодействующий противогрибковый агент рапамицин [123]. Сегодня это соединение используется в клинической практике в качестве иммуносупрессора и химиотерапевтического агента. Однако, начиная с 2009 г., многочисленные исследования на мышах продемонстрировали способность рапамицина замедлять проявления естественного процесса старения даже при начале терапии на поздних этапах жизни [124, 125]. В настоящее время ингибиторы mTOR являются единственным известным фармакологическим вмешательством, увеличивающим продолжительность жизни во всех протестированных экспериментальных моделях с использованием лабораторных животных. Полученные данные привели к появлению гипотезы, согласно которой, фармакологическое подавление mTORсигналинга может быть перспективным направлением лечения прогерии.

Принципиально новая информация о роли $\mathrm{mTOR}$ была получена при обработке рапамицином клеток больных синдромом Хатчинсона-Гилфорда. Подавление активности mTOR в клетках с повышенным содержанием прогерина способствовало активации процесса аутофагии, ускоряло утилизацию мутантного белка, восстанавливало структуру ядра, что существенно повышало пролиферативный потенциал клеток, который крайне низок при данном заболевании [14].

Таким образом, дальнейшие исследования эффектов рапамицина, а также молекулярных механизмов, опосредующих процесс развития преждевременного старения, имеют большое значение для понимания биологического старения в целом и для возможного создания в будущем «лекарств от старости».

\section{Метрелептин: современные возможности лечения липодистрофий}

Лечение прогероидных синдромов в настоящее время является в большей степени симптоматическим. Так, пациентам с липодистрофиями, часто сопровождающимися дислипидемией, тяжелой инсулинорезистентностью, сахарным диабетом и, в некоторых случаях, артериальной гипертензией, показано назначение 
сахароснижающих препаратов и гиполипидемических средств, соблюдение низкожировой диеты. Впервые исследование с участием 9 пациентов с липодистрофией в возрасте от 15 до 42 лет было проведено Oral EA. и coавт. в 2002 г. [126]. Подкожное введение метрелептина синтетического аналога лептина (рекомбинантной метиониловой производной человеческого лептина) дважды в день приводило к значительному улучшению гликемического контроля и липидного спектра. В 2014 г. препарат был одобрен Американским Агентством по контролю за пищевыми продуктами и медикаментами (FDA) для лечения генерализованных форм липодистрофии.

Эффективность и безопасность лечения метрелептином оценивались в проспективных открытых многоцентровых клинических исследованиях (NCT00005905, NCT00025883) в течение 14-летнего периода (2000-2014 гг.) с участием 66 пациентов с наследственной или приобретенной липодистрофией [127]. В течение всего периода наблюдения отмечалось значимое снижение уровня триглицеридов и гликированного гемоглобина (HbA1C). 6 из 39 пациентов (41\%), получавших препараты инсулина, 7 из 32 (21,9\%), принимавших пероральную сахароснижающую терапию, и 8 из 34 пациентов (23,5\%) - гиполипидемическую терапию, смогли прекратить прием соответствующих препаратов при лечении метрелептином. В настоящее время заместительная терапия рекомбинантным лептином значительно превышает эффективность всех других видов лечения генерализованных форм липодистрофий.

Лонафарниб (Lonafarnib) - перспективы лечения прогероидных ламинопатий

Progeria Research Foundation проводит исследование ингибитора фарнезилтрансферазы (препарат Lonafarnib), первоначально разработанного для лечения онкологических заболеваний. Первое клиническое испытание, проведенное на 25 пациентах с синдромом Хатчинсона-Гилфорда, показало положительный эффект от лечения в виде повышения массы тела, улучшения микроархитектоники костной ткани после двух лет применения препарата [128], увеличения медианы общей выживаемости с 14,6 до 16,2 лет [129]. В последующем аналогичный эффект от лечения был получен во второй фазе клинических испытаний [130].

Генная терапия, антисмысловые ингибиторы мРНК

Результаты ряда исследований свидетельствуют о возможности использования антисмысловых олигонуклеотидных последовательностей коротких интерферирующих РНК длиной от 8 до 50 нуклеотидов, связывающихся с матричной РНК (МРНК) по принципу комплементарности Уотсона-Крика и препятствующих дальнейшей трансляции мРНК в белок [131]. Эксперименты на мышах LmnaG609G/G609G с использованием технологии антисмысловых олигонуклеотидов продемонстрировали значительное снижение экспрессии мутантного белка прогерина, улучшение структуры и морфологии ядра, замедление старения фибробластов, увеличение максимальной и средней ожидаемой продолжительности жизни на $44 \%$ и $24 \%$ соответственно [132]. Однако оптимальное применение подобной технологии в лечении заболеваний человека требует ре- шения проблем, связанных с защитой олигонуклеотидов от преждевременного расщепления внутриклеточными нуклеазами и эффективной направленной доставкой антисмысловых лекарств.

\section{Бисфосфонаты}

Остеопороз, как широко распространенное заболевание, ассоциированное с возрастом, занимает ведущие позиции в структуре заболеваемости и смертности населения во всем мире. Согласно статистическим данным, летальность в течение первого года после перелома бедра составляет от 18 до 33\%, а более 50\% больных становятся нетрудоспособными и нуждаются в посторонней помощи [133].

Бисфосфонаты (БФ) - широко используемые антирезорбтивные препараты, назначаемые в комбинации с препаратами витамина D и кальция для предупреждения низкотравматичных переломов $[134,135]$.

Золедроновая кислота - наиболее активный азотсодержащий БФ, обладающий самой высокой константной сродства к гидроксиапатиту кости по сравнению с другими БФ. В двойном слепом рандомизированном плацебо-контролируемом исследовании HORIZON (The Health Outcomes and Reduced Incidence with Zoledronic Acid Once Yearly) с участием 7765 женщин с постменопаузальным остеопорозом лечение золедроновой кислотой в течение 3 лет приводило к снижению риска переломов позвонков на 70\%, переломов бедра - на $41 \%$ и периферических переломов - на 25\% по сравнению с группой плацебо, а также к достоверному снижению уровня биохимических маркеров костного обмена [136].

Влияние терапии золедроновой кислотой на частоту развития новых низкотравматических переломов и летальность после перелома проксимального отдела бедра в восстановительный период прицельно изучалась в исследовании HORIZON-RFT (HORIZON-Recurrent Fracture Trial), в котором приняли участие 2127 пациентов в возрасте старше 50 лет, получавших лечение золедроновой кислотой (5 мг однократно) или плацебо в первые 90 дней после хирургического лечения перелома шейки бедренной кости, а затем через каждые 12 месяцев [137]. По результатам исследования отмечено значимое снижение относительного риска (OP) развития новых переломов любой локализации на 35\% и риска летальности на 28\%. Снижение летальности на фоне лечения золедроновой кислотой нельзя было объяснить только снижением риска переломов, в связи с чем были проведены дополнительные исследования и метаанализы по изучению влияния других БФ на риск летальности.

Согласно проведенному крупному метаанализу Cummings SR. и соавт. [138], обобщившему результаты 38 клинических исследований, в 21 из которых оценивался эффект от терапии БФ и в 6 - от терапии золедроновой кислотой, не выявлено достоверной связи между всеми лекарственными препаратами для лечения остеопороза и общей смертностью (ОР 0,98; 95\% доверительный интервал (ДИ) 0,91-1,05), а также не получено положительных результатов относительно снижения общей смертности в клинических исследованиях с БФ (ОР 0,95; 95\% ДИ 0,86-1,04) и с золедроновой кислотой (ОР 0,88; 95\% ДИ 0,68-1,13). Вместе с тем, в ряде других объединенных исследований применение БФ было ассоцииро- 
вано со снижением летальности [139-141]. Так, в рамках многоцентрового рандомизированного исследования с участием 6120 пациентов в возрасте старше 50 лет было продемонстрировано снижение смертности в течение последующих 15 лет на 34\% в группе пациентов, получавших лечение алендроновой кислотой или ризедроновой кислотой (ОР 0,66; 95\% ДИ 0,48-0,91) по сравнению с нелечеными пациентами. Подобное исследование предоставляет дополнительные доказательства того, что лечение азотсодержащими БФ связано с лучшей выживаемостью и может принести существенную пользу пациентам с остеопорозом.

\section{Метформин}

Широко используемый в лечении сахарного диабета 2 типа препарат метформин часто рассматривается в клинических исследованиях в качестве средства для борьбы с возрастными заболеваниями. Метформин оказывает благоприятное влияние на метаболические и внутриклеточные процессы, увеличивает количество поступающего в клетки кислорода, подавляет системное воспаление, ингибирует старение клеток, снижает секрецию SA- $\beta$-gal и SASP [142]. На стадии доклинических исследований было показано увеличение средней продолжительности жизни грызунов на 40\% и отсроченное развитие возрастных заболеваний [143].

Несколько эпидемиологических исследований и данные метаанализов продемонстрировали снижение общей заболеваемости и смертности от 3НО при применении метформина [144-146]. В ряде исследований на клеточной культуре показана способность препарата подавлять рост и пролиферацию опухолевых клеток, индуцировать апоптоз, вызывать остановку клеточного цикла [147-149]. Препарат значительно снижает риск развития меланомы [150], рака предстательной железы [151], легких [152], молочной железы [153], пищевода [154], толстой кишки [155]. Метаанализ 47 исследований, проведенных в общей сложности на 65540 пациентах, показал, что лечение метформином снижало заболеваемость и смертность от $3 \mathrm{HO}$ на $31 \%$ и 34\% соответственно [156]. Кроме того, в исследовании UKPDS (UK Prospective Diabetes Study) было показано снижение смертности от всех причин на 36\% на фоне лечения метформином в сравнении с лечением инсулином и другими сахароснижающими препаратами, а также достоверное снижение риска развития сердечно-сосудистых заболеваний и инсульта [157].

\section{ЗАКЛЮЧЕНИЕ}

Таким образом, изучение генетических причин прогероидных синдромов помогает понять механизмы развития возрастных изменений. Разработка методов лечения прогерий, в свою очередь, может быть перспективным направлением для коррекции возрастных изменений человека и увеличения продолжительности жизни. Препараты для лечения заболеваний, ассоциированных с возрастом, таких как остеопороз, сахарный диабет, онкопатология, по результатам ряда исследований, оказывают дополнительное влияние на увеличение продолжительности жизни, что невозможно объяснить основным клиническим эффектом. Дальнейшее изучение механизмов действия препаратов, которые имеют потенциал по увеличению продолжительности жизни, позволит лучше понять патогенез возрастных изменений и увеличит возможности разработок более эффективных методов коррекции заболеваний, ассоциированных с возрастом.

\section{ДОПОЛНИТЕЛЬНАЯ ИНФОРМАЦИЯ}

Конфликт интересов. Авторы декларируют отсутствие явных и потенциальных конфликтов интересов, связанных с публикацией настоящей статьи.

Участие авторов. Все авторы внесли значимый вклад в проведение поисково-аналитической работы и подготовку статьи, прочли и одобрили финальную версию до публикации.

\section{СПИСОК ЛИТЕРАТУРЫ | REFERENCES}

1. López-Otín C, Blasco MA, Partridge L, et al. The Hallmarks of Aging. Cell. 2013;153(6):1194-1217. doi: https://doi.org/10.1016/j.cell.2013.05.039

2. Kudlow BA, Kennedy BK, Monnat RJ, Jr. Werner and HutchinsonGilford progeria syndromes: mechanistic basis of human progeroid diseases. Nat Rev Mol Cell Biol. 2007;8(5):394-404. doi: https://doi.org/10.1038/nrm2161

3. Hutchinson J. Congenital Absence of Hair and Mammary Glands with Atrophic Condition of the Skin and its Appendages, in a Boy whose Mother had been almost wholly Bald from Alopecia Areata from the age of Six. Med Chir Trans. 1886;69:473-477. doi: https://doi.org/10.1177/095952878606900127

4. Gilford H. On a Condition of Mixed Premature and Immature Development. Med Chir Trans. 1897;80:17-46 25. doi: https://doi.org/10.1177/095952879708000105

5. Werner O. On cataract in conjunction with scleroderma. In: Salk D, Fujiwara Y, Martin GM, editors. Werner's Syndrome and Human Aging. Advances in Experimental Medicine and Biology. Vol. 190. Boston: Springer; 1985. p. 1-14. doi: https://doi.org/10.1007/978-1-4684-7853-2_1.

6. Rautenstrauch T, Snigula F. Progeria: a cell culture study and clinical report of familial incidence. Eur J Pediatr. 1977;124(2):101-111. doi: https://doi.org/10.1007/bf00477545

7. Wiedemann HR. An unidentified neonatal progeroid syndrome: follow-up report. Eur J Pediatr. 1979;130(1):65-70. doi: https://doi.org/10.1007/bf00441901
8. Wambach JA, Wegner DJ, Patni N, et al. Bi-allelic POLR3A Lossof-Function Variants Cause Autosomal-Recessive WiedemannRautenstrauch Syndrome. Am J Hum Genet. 2018;103(6):968-975. doi: https://doi.org/10.1016/j.ajhg.2018.10.010

9. Paolacci S, Li Y, Agolini E, et al. Specific combinations of biallelic POLR3A variants cause WiedemannRautenstrauch syndrome. J Med Genet. 2018;55(12):837-846. doi: https://doi.org/10.1136/jmedgenet-2018-105528

10. Paolacci S, Bertola D, Franco J, et al. Wiedemann-Rautenstrauch syndrome: A phenotype analysis. Am J Med Genet A. 2017;173(7):1763-1772. doi: https://doi.org/10.1002/ajmg.a.38246

11. Becerra $\mathrm{CH}$, Contreras-Garcia GA, Perez Vera $L A$, et al. Wiedemann-Rautenstrauch syndrome prenatal diagnosis. J Perinatol. 2014;34(12):954-956. doi: https://doi.org/10.1038/jp.2014.156

12. Beauregard-Lacroix E, Salian S, Kim H, et al. A variant of neonatal progeroid syndrome, or WiedemannRautenstrauch syndrome, is associated with a nonsense variant in POLR3GL. Eur J Hum Genet. 2020;28(4):461-468. doi: https://doi.org/10.1038/s41431-019-0539-6

13. Gargiuli C, Schena E, Mattioli E, et al. Lamins and bone disorders: current understanding and perspectives. Oncotarget. 2018;9(32):22817-22831. doi: https://doi.org/10.18632/oncotarget.25071 
14. Дадали ЕЛ., Билева Д.С. Угаров И.В. Клинико-генетическая характеристика наследственных ламинопатий. // Анналы клинической и экспериментальной неврологии. - 2008. T. 2. — №4. — C. 28-33. [Dadaly EL, Bileva DS, Ugarov IV. Clinical and genetic characteristics of hereditary laminopathies. Annaly klinicheskoy i eksperimental'noy nevrologii. 2008;2(4):28-33. (In Russ.)]

15. Gonzalo S, Kreienkamp R, Askjaer P. Hutchinson-Gilford Progeria Syndrome: A premature aging disease caused by LMNA gene mutations. Ageing Res Rev. 2017;33:18-29. doi: https://doi.org/10.1016/j.arr.2016.06.007

16. Ashapkin W, Kutueva LI, Kurchashova SY, Kireev II. Are There Common Mechanisms Between the Hutchinson-Gilford Progeria Syndrome and Natural Aging? Front Genet. 2019;10. doi: https://doi.org/10.3389/fgene.2019.00455

17. Turgay $Y$, Eibauer M, Goldman AE, et al. The molecular architecture of lamins in somatic cells. Nature. 2017;543(7644):261-264. doi: https://doi.org/10.1038/nature21382

18. Лаврушкина С.В., Овсянникова Н.Л., Юдина А.С., и др. Канцерогенез и старение: взгляд со стороны ядерной ламины. // Цитология. - 2018. — T. 60. — №11. — C. 892-894. [Lavrushlina SV, Ovsyannikova NL, Yudina AS, et al. Carcinogenesis and ageing: a view from nuclear lamina. Cell and tissue biology. 2018;60(11):892-894. (In Russ.)] doi: https://doi.org/10.1134/S0041377118110056.

19. Swahari V, Nakamura A. Speeding up the clock: The past, present and future of progeria. Dev Growth Differ. 2016;58(1):116-130. doi: https://doi.org/10.1111/dgd.12251

20. Piekarowicz K, Machowska M, Dzianisava V, Rzepecki R. Hutchinson-Gilford Progeria Syndrome-Current Status and Prospects for Gene Therapy Treatment. Cells. 2019;8(2):88. doi: https://doi.org/10.3390/cells8020088

21. Politano L, Lattanzi G, Benedetti S, et al. Emerging perspectives on laminopathies. Cell Health Cytoskelet. 2016:25. doi: https://doi.org/10.2147/chc.559507

22. Hamczyk MR, del Campo L, Andrés V. Aging in the Cardiovascular System: Lessons from HutchinsonGilford Progeria Syndrome. Annu Rev Physiol. 2018;80(1):27-48. doi: https://doi.org/10.1146/annurev-physiol-021317-121454

23. Navarro CL, Esteves-Vieira V, Courrier S, et al. New ZMPSTE24 (FACE1) mutations in patients affected with restrictive dermopathy or related progeroid syndromes and mutation update. Eur J Hum Genet 2013;22(8):1002-1011. doi: https://doi.org/10.1038/ejhg.2013.258

24. McKenna T, Sola Carvajal A, Eriksson M. Skin Disease in LaminopathyAssociated Premature Aging. J Invest Dermatol. 2015;135(11):2577-2583. doi: https://doi.org/10.1038/jid.2015.295

25. Filesi I, Gullotta F, Lattanzi G, et al. Alterations of nuclear envelope and chromatin organization in mandibuloacral dysplasia, a rare form of laminopathy. Physiol Genomics. 2005;23(2):150-158. doi: https://doi.org/10.1152/physiolgenomics.00060.2005

26. Yaou RB, Navarro C, Quijano-Roy S, et al. Type B mandibuloacral dysplasia with congenital myopathy due to homozygous ZMPSTE24 missense mutation. Eur J Hum Genet. 2011;19(6):647-654. doi: https://doi.org/10.1038/ejhg.2010.256

27. Соркина Е.Л., Тюльпаков А.Н. Наследственные и приобретенные липодистрофии: молекулярно-генетические и аутоиммунные механизмы. // Ожирение и метаболизм. - 2018. - Т. 15. — №1. - C. 39-42. [Sorkina EL, Tyulpakov AN. Inherited and acquired lipodystrophies: molecular-genetic and autoimmune mechanisms. Obesity and metabolism. 2018;15(1):39-42. (In Russ.)] doi: https://doi.org/10.14341/OMET2018139-42

28. Bachrati CZ, Hickson ID. RecQ helicases: suppressors of tumorigenesis and premature aging. Biochem J. 2003;374(Pt 3):577-606. doi: https://doi.org/10.1042/BJ20030491

29. Croteau DL, Popuri V, Opresko PL, Bohr VA. Human RecQ helicases in DNA repair, recombination, and replication. Annu Rev Biochem. 2014;83:519-552. doi: https://doi.org/10.1146/annurev-biochem-060713-035428

30. Guo RB, Rigolet $\mathrm{P}$, Ren $\mathrm{H}$, et al. Structural and functional analyses of disease-causing missense mutations in Bloom syndrome protein. Nucleic Acids Res. 2007;35(18):6297-6310. doi: https://doi.org/10.1093/nar/gkm536

31. Larizza L, Magnani I, Roversi G. Rothmund-Thomson syndrome and RECQL4 defect: splitting and lumping. Cancer Lett. 2006;232(1):107-120. doi: https://doi.org/10.1016/j.canlet.2005.07.042

32. Shamanna RA, Croteau DL, Lee JH, Bohr VA. Recent Advances in Understanding Werner Syndrome. F1000Res. 2017;6:1779. doi: https://doi.org/10.12688/f1000research.12110.1
33. O'Sullivan RJ, Karlseder J. Telomeres: protecting chromosomes against genome instability. Nat Rev Mol Cell Biol. 2010;11(3):171-181. doi: https://doi.org/10.1038/nrm2848

34. Johnson JE, Cao K, Ryvkin P, et al. Altered gene expression in the Werner and Bloom syndromes is associated with sequences having G-quadruplex forming potential. Nucleic Acids Res. 2010;38(4):1114-1122. doi: https://doi.org/10.1093/nar/gkp1103

35. Драпкина О.М., Шепель Р.Н. Теломеры и теломеразный комплекс. Основные клинические проявления генетического сбоя // Кардиоваскулярная терапия и профилактика. - 2015. Т.14. №1. - C. 70-77. [Drapkina OM, Shepel RN. Telomeres and telomerase complex. The main clinical manifestation of genetic malfunctioning. Cardiovascular Therapy and Prevention 2015;14(1):70-77. (In Russ.)] doi: https://doi.org/10.15829/1728-8800-2015-1-70-77

36. Tang W, Robles Al, Beyer RP, et al. The Werner syndrome RECQ helicase targets G4 DNA in human cells to modulate transcription. Hum Mol Genet. 2016;25(10):2060-2069. doi: https://doi.org/10.1093/hmg/ddw079

37. Ishikawa N, Nakamura K-I, Izumiyama-Shimomura N, et al. Accelerated <i>in vivo</i> epidermal telomere loss in Werner syndrome. Aging. 2011;3(4):417-429. doi: https://doi.org/10.18632/aging.100315

38. Maierhofer A, Flunkert J, Oshima J, et al. Accelerated epigenetic aging in Werner syndrome. Aging. 2017;9(4):1143-1152. doi: https://doi.org/10.18632/aging.101217

39. Zhang W, Li J, Suzuki K, et al. A Werner syndrome stem cell model unveils heterochromatin alterations as a driver of human aging. Science. 2015;348(6239):1160-1163. doi: https://doi.org/10.1126/science.aaa1356

40. Sarbacher CA, Halper JT. Connective Tissue and AgeRelated Diseases. Subcell Biochem. 2019;91:281-310. doi: https://doi.org/10.1007/978-981-13-3681-2_11

41. Masala MV, Scapaticci S, Olivieri C, et al. Epidemiology and clinical aspects of Werner's syndrome in North Sardinia: description of a cluster. Eur J Dermatol. 2007;17(3):213-216. doi: https://doi.org/10.1684/ejd.2007.0155

42. Yokote $K$, Chanprasert S, Lee L, et al. WRN Mutation Update: Mutation Spectrum, Patient Registries, and Translational Prospects. Hum Mutat. 2017;38(1):7-15. doi: https://doi.org/10.1002/humu.23128

43. Nishimura EK, Granter SR, Fisher DE. Mechanisms of hair graying: incomplete melanocyte stem cell maintenance in the niche. Science. 2005;307(5710):720-724. doi: https://doi.org/10.1126/science.1099593

44. Oshima J, Sidorova JM, Monnat RJ, Jr. Werner syndrome: Clinical features, pathogenesis and potential therapeutic interventions. Ageing Res Rev. 2017:33:105-114. doi: https://doi.org/10.1016/j.arr.2016.03.002

45. Lessel D, Kubisch C. Hereditary Syndromes with Signs of Premature Aging. Dtsch Arztebl Int. 2019;1 16(29-30):489-496. doi: https://doi.org/10.3238/arztebl.2019.0489

46. Ozturk M, Akdeniz N, Ayakta H, Kosem M. A brother and sister with Werner's syndrome demonstrating extensive tendon calcification and sacroiliitis. Clin Exp Dermatol. 2006;31(4):615-616. doi: https://doi.org/10.1111/j.1365-2230.2006.02130.x

47. Honjo S, Yokote K, Fujimoto M, et al. Clinical outcome and mechanism of soft tissue calcification in Werner syndrome. Rejuvenation Res. 2008;11(4):809-819. doi: https://doi.org/10.1089/rej.2007.0649

48. Leone A, Costantini AM, Brigida R, et al. Soft-tissue mineralization in Werner syndrome. Skeletal Radiol. 2005;34(1):47-51. doi: https://doi.org/10.1007/s00256-004-0792-8

49. Sickles CK, Gross GP. Progeria (Werner Syndrome). Treasure Island: StatPearls Publishing; 2020.

50. Belaya ZE, Grebennikova TA, Yashina JN, et al. Rare causes of secondary hyperparathyroidism clinical cases of Werner's syndrome, Gitelman's syndrome and osteopetrosis among patients referred for primary hyperparathyroidism. In: Osteoporosis International. Vol. 26. London: Springer; 2015. p. 111.

51. Lauper JM, Krause A, Vaughan TL, Monnat RJ, Jr. Spectrum and risk of neoplasia in Werner syndrome: a systematic review. PLoS One. 2013;8(4):e59709. doi: https://doi.org/10.1371/journal.pone.0059709

52. de Renty C, Ellis NA. Bloom's syndrome: Why not premature aging?: A comparison of the BLM and WRN helicases. Ageing Res Rev. 2017;33:36-51. doi: https://doi.org/10.1016/j.arr.2016.05.010

53. Bloom D. congenital telangiectatic erythema resembling lupus erythematosus in dwarfs<subtitle>Probably a Syndrome Entity. Arch Pediatr Adolesc Med. 1954;88(6):754. doi: https://doi.org/10.1001/archpedi.1954.02050100756008 
54. German J, Sanz MM, Ciocci S, et al. Syndrome-causing mutations of the BLM gene in persons in the Bloom's Syndrome Registry. Hum Mutat. 2007;28(8):743-753. doi: https://doi.org/10.1002/humu.20501

55. Fares F, Badarneh $\mathrm{K}$, Abosaleh M, et al. Carrier frequency of autosomal-recessive disorders in the Ashkenazi Jewish population: should the rationale for mutation choice for screening be reevaluated? Prenat Diagn. 2008;28(3):236-241. doi: https://doi.org/10.1002/pd.1943

56. Kaneko H, Kondo N. Clinical features of Bloom syndrome and function of the causative gene, BLM helicase. Expert Rev Mol Diagn 2004;4(3):393-401. doi: https://doi.org/10.1586/14737159.4.3.393

57. Lu L, Jin W, Wang LL. Aging in Rothmund-Thomson syndrome and related RECQL4 genetic disorders. Ageing Res Rev. 2017;33:30-35. doi: https://doi.org/10.1016/j.arr.2016.06.002

58. Thomson MS. Poikiloderma Congenitale: Two Cases for Diagnosis Proc R Soc Med. 1936;29(5):453-455

59. Colombo EA, Locatelli A, Cubells Sanchez L, et al. RothmundThomson Syndrome: Insights from New Patients on the Genetic Variability Underpinning Clinical Presentation and Cancer Outcome. Int J Mol Sci. 2018;19(4). doi: https://doi.org/10.3390/ijms19041103

60. Oshima J, Kato H, Maezawa Y, Yokote K. RECQ helicase disease and related progeroid syndromes: RECQ2018 meeting. Mech Ageing Dev. 2018;173:80-83. doi: https://doi.org/10.1016/j.mad.2018.05.002

61. Hafsi W, Badri T. Poikiloderma Congenitale. Treasure Island (FL): StatPearls Publishing; 2019.

62. Araujo SJ, Kuraoka I. Nucleotide excision repair genes shaping embryonic development. Open Biol. 2019;9(10):190166. doi: https://doi.org/10.1098/rsob.190166

63. Spivak G. Nucleotide excision repair in humans. DNA Repair (Amst). 2015;36:13-18. doi: https://doi.org/10.1016/j.dnarep.2015.09.003

64. Moriwaki S, Kanda F, Hayashi M, et al. Xeroderma pigmentosum clinical practice guidelines. J Dermatol. 2017;44(10):1087-1096. doi: https://doi.org/10.1111/1346-8138.13907

65. Brooks BP, Thompson AH, Bishop RJ, et al. Ocular manifestations of xeroderma pigmentosum: long-term follow-up highlights the role of DNA repair in protection from sun damage. Ophthalmology. 2013;120(7):1324-1336. doi: https://doi.org/10.1016/j.ophtha.2012.12.044

66. Bradford PT, Goldstein AM, Tamura D, et al. Cancer and neurologic degeneration in xeroderma pigmentosum: long term follow-up characterises the role of DNA repair. J Med Genet. 2011;48(3):168-176. doi: https://doi.org/10.1136/jmg.2010.083022

67. Karass M, Naguib MM, Elawabdeh N, et al. Xeroderma pigmentosa: three new cases with an in depth review of the genetic and clinical characteristics of the disease. Fetal Pediatr Pathol. 2015;34(2):120-127. doi: https://doi.org/10.3109/15513815.2014.982336

68. Kaliki S, Jajapuram SD, Maniar A, Mishra DK. Ocular and Periocular Tumors in Xeroderma Pigmentosum: A Study of 120 Asian Indian Patients. Am J Ophthalmol. 2019;198:146-153. doi: https://doi.org/10.1016/j.ajo.2018.10.011

69. Black JO. Xeroderma Pigmentosum. Head Neck Pathol. 2016;10(2):139-144. doi: https://doi.org/10.1007/s12105-016-0707-8

70. Cockayne EA. Dwarfism with retinal atrophy and deafness. Arch Dis Child. 1936;11(61):1-8. doi: https://doi.org/10.1136/adc.11.61.1

71. Wilson BT, Stark Z, Sutton RE, et al. The Cockayne Syndrome Natural History (CoSyNH) study: clinical findings in 102 individuals and recommendations for care. Genet Med. 2016;18(5):483-493. doi: https://doi.org/10.1038/gim.2015.110

72. Слижов П.А., Долинина Т.И., Плескай Н.М., и др. Маркеры старения в клетках больных синдромом Коккейна. Общие и индивидуальные различия. // Цитология. - 2018. — Т. 60. №3. - C. 188-199. [Slizhov PA, Dolinina TI, Pleskach NM, et al. Aging markers in cells of patients with Cockayne Syndrome. General and individual differences. Cell and tissue biology. 2018;60(3):188-199. (In Russ.)] doi: https://doi.org/10.31116/tsitol.2018.03.05

73. Kubota M, Ohta S, Ando A, et al. Nationwide survey of Cockayne syndrome in Japan: Incidence, clinical course and prognosis. Pediatr Int. 2015;57(3):339-347. doi: https://doi.org/10.1111/ped.12635

74. Karikkineth AC, Scheibye-Knudsen M, Fivenson E, et al. Cockayne syndrome: Clinical features, model systems and pathways. Ageing Res Rev. 2017;33:3-17. doi: https://doi.org/10.1016/j.arr.2016.08.002

75. Kalantaridou SN, Zoumakis E, Makrigiannakis A, et al. Corticotropin-releasing hormone, stress and human reproduction: an update. J Reprod Immunol. 2010;85(1):33-39. doi: https://doi.org/10.1016/j.jri.2010.02.005
76. Hayashi M, Miwa-Saito N, Tanuma N, Kubota M. Brain vascular changes in Cockayne syndrome. Neuropathology. 2012;32(2):113-117. doi: https://doi.org/10.1111/j.1440-1789.2011.01241.x

77. Kraemer KH, Patronas NJ, Schiffmann R, et al. Xeroderma pigmentosum, trichothiodystrophy and Cockayne syndrome: a complex genotypephenotype relationship. Neuroscience. 2007;145(4):1388-1396. doi: https://doi.org/10.1016/j.neuroscience.2006.12.020

78. Pereira LB, Valente NYS, Rocha VB. Do you know this syndrome? Ichthyosis associated with neurological condition and alteration of hairs. An Bras Dermatol. 2018;93(1):135-137. doi: https://doi.org/10.1590/abd1806-4841.20187727

79. Farmaki E, Nedelkopoulou N, Delli F, et al. Brittle Hair, Photosensitivity, Brain Hypomyelination and Immunodeficiency: Clues to Trichothiodystrophy. Indian J Pediatr. 2017;84(1):89-90. doi: https://doi.org/10.1007/s12098-016-2209-9

80. Potter H, Chial HJ, Caneus J, et al. Chromosome Instability and Mosaic Aneuploidy in Neurodegenerative and Neurodevelopmental Disorders. Front Genet. 2019;10:1092 doi: https://doi.org/10.3389/fgene.2019.01092

81. Khetarpal P, Das S, Panigrahi I, Munshi A. Primordial dwarfism: overview of clinical and genetic aspects. Mol Genet Genomics. 2016;291(1):1-15. doi: https://doi.org/10.1007/s00438-015-1110-y

82. O'Driscoll M, Ruiz-Perez VL, Woods CG, et al. A splicing mutation affecting expression of ataxia-telangiectasia and Rad3-related protein (ATR) results in Seckel syndrome. Nat Genet. 2003;33(4):497-501. doi: https://doi.org/10.1038/ng1129

83. Qvist P, Huertas P, Jimeno S, et al. CtIP Mutations Cause Seckel and Jawad Syndromes. PLoS Genet. 2011;7(10):e1002310. doi: https://doi.org/10.1371/journal.pgen.1002310

84. Al-Dosari MS, Shaheen R, Colak D, Alkuraya FS. Novel CENPJ mutation causes Seckel syndrome. J Med Genet. 2010;47(6):411-414. doi: https://doi.org/10.1136/jmg.2009.076646

85. Kalay E, Yigit G, Aslan Y, et al. CEP152 is a genome maintenance protein disrupted in Seckel syndrome. Nat Genet. 2011;43(1):23-26. doi: https://doi.org/10.1038/ng.725

86. Sir JH, Barr AR, Nicholas AK, et al. A primary microcephaly protein complex forms a ring around parental centrioles. Nat Genet. 2011;43(11):1147-1153. doi: https://doi.org/10.1038/ng.971

87. Dauber A, Lafranchi SH, Maliga Z, et al. Novel microcephalic primordial dwarfism disorder associated with variants in the centrosomal protein ninein. J Clin Endocrinol Metab. 2012;97(11):E2140-2151. doi: https://doi.org/10.1210/jc.2012-2150

88. Shaheen R, Faqeih E, Ansari S, et al. Genomic analysis of primordial dwarfism reveals novel disease genes. Genome Res. 2014;24(2):291-299. doi: https://doi.org/10.1101/gr.160572.113

89. Ogi T, Walker S, Stiff T, et al. Identification of the first ATRIP-deficient patient and novel mutations in ATR define a clinical spectrum for ATR-ATRIP Seckel Syndrome. PLoS Genet. 2012;8(11):e1002945. doi: https://doi.org/10.1371/journal.pgen.1002945

90. Barbelanne M, Tsang WY. Molecular and cellular basis of autosomal recessive primary microcephaly. Biomed Res Int. 2014;2014:547986. doi: https://doi.org/10.1155/2014/547986

91. Savage SA. Dyskeratosis Congenita. In: Adam MP, Ardinger HH, Pagon RA, et al, editors. GeneReviews ${ }^{\oplus}$. Seattle (WA): University of Washington, Seattle; 1993-2020.

92. Sharma RK, Gupta M, Sood S, Gupta A. Dyskeratosis congenita: presentation of cutaneous triad in a sporadic case. BMJ Case Rep. 2018;11(1). doi: https://doi.org/10.1136/bcr-2018-226736

93. Aplas V. Poikiloderma, parapsoriasis and atrophia cutis cum pigmentatione, dystrophia ungium et leukoplakia oris Zinsser so-called dyskeratosis congenita. Arch Klin Exp Dermatol. 1956;202(3):224-237. doi: https://doi.org/10.1007/bf00476707

94. Wang F, Du YQ, Gong W, et al. Research progress of dyskeratosis congenita. Zhonghua Kou Qiang Yi Xue Za Zhi. 2019;54(2):130-134. doi: https://doi.org/10.3760/cma.j.issn.1002-0098.2019.02.010

95. Savage SA, Bertuch AA. The genetics and clinical manifestations of telomere biology disorders. Genet Med. 2010;12(12):753-764 doi: https://doi.org/10.1097/GIM.0b013e3181f415b5

96. Dodson LM, Baldan A, Nissbeck M, et al. From incomplete penetrance with normal telomere length to severe disease and telomere shortening in a family with monoallelic and biallelic PARN pathogenic variants. Hum Mutat. 2019;40(12):2414-2429. doi: https://doi.org/10.1002/humu.23898

97. Savage SA. Beginning at the ends: telomeres and human disease. F1000Res. 2018;7. doi: https://doi.org/10.12688/f1000research.14068.1 
98. Kutbay NO, Yurekli BS, Erdemir Z, et al. A case of dyskeratosis congenita associated with hypothyroidism and hypogonadism. Hormones (Athens). 2016;15(2):297-299. doi: https://doi.org/10.14310/horm.2002.1655

99. Shomali W, Brar R. Late presentation of dyskeratosis congenita. Br J Haematol. 2019;187(3):273. doi: https://doi.org/10.1111/bjh.16131

100. Du H, Guo Y, Ma D, et al. A case report of heterozygous TINF2 gene mutation associated with pulmonary fibrosis in a patient with dyskeratosis congenita. Medicine (Baltimore). 2018;97(19):e0724. doi: https://doi.org/10.1097/MD.0000000000010724

101. de Boer J, Andressoo JO, de Wit J, et al. Premature aging in mice deficient in DNA repair and transcription. Science. 2002;296(5571):1276-1279. doi: https://doi.org/10.1126/science.1070174

102. Wilson AS, Power BE, Molloy PL. DNA hypomethylation and human diseases. Biochim Biophys Acta. 2007;1775(1):138-162. doi: https://doi.org/10.1016/j.bbcan.2006.08.007

103. Zhang W, Li J, Suzuki K, et al. Aging stem cells. A Werner syndrome stem cell model unveils heterochromatin alterations as a driver of human aging. Science. 2015;348(6239):1160-1163. doi: https://doi.org/10.1126/science.aaa1356

104. Shumaker DK, Dechat T, Kohlmaier A, et al. Mutant nuclea lamin A leads to progressive alterations of epigenetic control in premature aging. Proc Natl Acad Sci U S A. 2006;103(23):8703-8708. doi: https://doi.org/10.1073/pnas.0602569103

105. Davis T, Brook AJ, Rokicki MJ, et al. Evaluating the Role of p38 MAPK in the Accelerated Cell Senescence of Werner Syndrome Fibroblasts. Pharmaceuticals (Basel). 2016;9(2). doi: https://doi.org/10.3390/ph9020023

106. Tivey HS, Brook AJ, Rokicki MJ, et al. p38 (MAPK) stress signalling in replicative senescence in fibroblasts from progeroid and genomic instability syndromes. Biogerontology. 2013;14(1):47-62. doi: https://doi.org/10.1007/s10522-012-9407-2

107. Bagley MC, Davis T, Murziani PG, et al. Use of p38 MAPK Inhibitors for the Treatment of Werner Syndrome. Pharmaceuticals (Basel). 2010;3(6):1842-1872. doi: https://doi.org/10.3390/ph3061842

108. Yamaga M, Takemoto M, Shoji M, et al. Werner syndrome: a model for sarcopenia due to accelerated aging. Aging (Albany NY). 2017;9(7):1738-1744. doi: https://doi.org/10.18632/aging.101265

109. von Walden F, Liu C, Aurigemma N, Nader GA. mTOR signaling regulates myotube hypertrophy by modulating protein synthesis, rDNA transcription, and chromatin remodeling. Am J Physiol Cell Physiol. 2016;311(4):C663-C672. doi: https://doi.org/10.1152/ajpcell.00144.2016

110. Dormond O. mTOR in Human Diseases. Int J Mol Sci. 2019;20(9). doi: https://doi.org/10.3390/ijms20092351

111. Ou HL, Schumacher B. DNA damage responses and p53 in the aging process. Blood. 2018;131(5):488-495. doi: https://doi.org/10.1182/blood-2017-07-746396

112. Wu D, Prives C. Relevance of the p53-MDM2 axis to aging. Cell Death Differ. 2018;25(1):169-179. doi: https://doi.org/10.1038/cdd.2017.187

113. Inoki K, Ouyang H, Li Y, Guan KL. Signaling by target of rapamycin proteins in cell growth control. Microbio/ Mol Biol Rev. 2005;69(1):79-100. doi: https://doi.org/10.1128/MMBR.69.1.79-100.2005

114. Weichhart T. mTOR as Regulator of Lifespan, Aging, and Cellular Senescence: A Mini-Review. Gerontology. 2018;64(2):127-134. doi: https://doi.org/10.1159/000484629

115. Wiza C, Nascimento EB, Ouwens DM. Role of PRAS40 in Akt and mTOR signaling in health and disease. Am J Physiol Endocrinol Metab. 2012;302(12):E1453-1460. doi: https://doi.org/10.1152/ajpendo.00660.2011

116. Shaw RJ, Bardeesy N, Manning BD, et al. The LKB1 tumor suppressor negatively regulates mTOR signaling. Cancer Cell. 2004;6(1):91-99. doi: https://doi.org/10.1016/j.ccr.2004.06.007

117. Mammucari C, Milan G, Romanello V, et al. FoxO3 controls autophagy in skeletal muscle in vivo. Cell Metab. 2007;6(6):458-471. doi: https://doi.org/10.1016/j.cmet.2007.11.001

118. Zhao J, Brault JJ, Schild A, et al. FoxO3 coordinately activates protein degradation by the autophagic/lysosomal and proteasomal pathways in atrophying muscle cells. Cell Metab. 2007:6(6):472-483. doi: https://doi.org/10.1016/j.cmet.2007.11.004

119. Wu JJ, Liu J, Chen EB, et al. Increased mammalian lifespan and a segmental and tissue-specific slowing of aging after genetic reduction of mTOR expression. Cell Rep. 2013;4(5):913-920. doi: https://doi.org/10.1016/j.celrep.2013.07.030
120. Vellai T, Takacs-Vellai K, Zhang Y et al. Genetics: influence of TOR kinase on lifespan in C. elegans. Nature. 2003;426(6967):620. doi: https://doi.org/10.1038/426620a

121. Bjedov I, Toivonen JM, Kerr F, et al. Mechanisms of life span extension by rapamycin in the fruit fly Drosophila melanogaster. Cell Metab. 2010;11(1):35-46. doi: https://doi.org/10.1016/j.cmet.2009.11.010

122. Kaeberlein M, Powers RW, 3rd, Steffen KK, et al Regulation of yeast replicative life span by TOR and Sch9 in response to nutrients. Science. 2005;310(5751):1193-1196. doi: https://doi.org/10.1126/science.1115535

123. Seto B. Rapamycin and mTOR: a serendipitous discovery and implications for breast cancer. Clin Trans/ Med. 2012;1 (1):29 doi: https://doi.org/10.1186/2001-1326-1-29

124. Demidenko ZN, Zubova SG, Bukreeva El, et al. Rapamycin decelerates cellular senescence. Cell Cycle. 2009;8(12):1888-1895. doi: https://doi.org/10.4161/cc.8.12.8606

125. Harrison DE, Strong R, Sharp ZD, et al. Rapamycin fed late in life extends lifespan in genetically heterogeneous mice. Nature. 2009:460(7253):392-395. doi: https://doi.org/10.1038/nature08221

126. Oral EA, Simha V, Ruiz E, et al. Leptin-replacement therapy for lipodystrophy. N Engl J Med. 2002;346(8):570-578. doi: https://doi.org/10.1056/NEJMoa012437

127. Brown RJ, Oral EA, Cochran E, et al. Long-term effectiveness and safety of metreleptin in the treatment of patients with generalized lipodystrophy. Endocrine. 2018;60(3):479-489. doi: https://doi.org/10.1007/s12020-018-1589-1

128. Gordon LB, Kleinman ME, Miller DT, et al. Clinical trial of a farnesyltransferase inhibitor in children with Hutchinson-Gilford progeria syndrome. Proc Natl Acad Sci U S A. 2012;109(41):16666-16671. doi: https://doi.org/10.1073/pnas.1202529109

129. Gordon LB, Massaro J, D’Agostino RB, Sr., et al. Impact of farnesylation inhibitors on survival in HutchinsonGilford progeria syndrome. Circulation. 2014;130(1):27-34. doi: https://doi.org/10.1161/CIRCULATIONAHA.113.008285

130. Gordon LB, Shappell H, Massaro J, et al. Association of Lonafarnib Treatment vs No Treatment With Mortality Rate in Patients With Hutchinson-Gilford Progeria Syndrome. JAMA. 2018;319(16):1687-1695. doi: https://doi.org/10.1001/jama.2018.3264

131. McNally EM, Wyatt EJ. Welcome to the splice age: antisense oligonucleotide-mediated exon skipping gains wider applicability. J Clin Invest. 2016;126(4):1236-1238. doi: https://doi.org/10.1172/JCl86799

132. Lee JM, Nobumori C, Tu Y, et al. Modulation of LMNA splicing as a strategy to treat prelamin A diseases. J Clin Invest. 2016;126(4):1592-1602. doi: https://doi.org/10.1172/JCl85908

133. Ершова О.Б., Белова К.Ю., Дегтярев А.А., и др. Анализ летальности у пациентов с переломом проксимального отдела бедра. // Остеопороз и остеопатии. - 2015. - Т. 18. №3. - C. 3-8. [Ershova OB, Belova KY, Degtyarev AA, et al. Analysis of mortality in patients with a fracture of the proximal femur. Osteoporosis and bone diseases. 2015;18(3):3-8. (In Russ.)] doi: https://doi.org/10.14341/osteo201533-8

134. Мельниченко Г.А., Белая Ж.Е., Рожинская Л.Я., и др. Краткое изложение клинических рекомендаций по диагностике и лечению остеопороза Российской ассоциации эндокринологов. // Остеопороз и остеопатии. - 2016. - Т. 19. №3. - C. 28-36. [Melnichenko GA, Belaya ZE, Rozhinskaya LY, et al. Summary of clinical guidelines for the diagnosis and treatment of osteoporosis of the Russian association of endocrinologists. Osteoporosis and bone diseases 2016;19(3):28-36. (In Russ.)] doi: https://doi.org/10.14341/osteo2016328-36

135. Белая Ж.Е., Рожинская Л.Я. Витамин D в терапии остеопороза: его роль в комбинации с препаратами для лечения остеопороза, внескелетные эффекты. // Эффективная фармакотерапия. 2013. — T. 38. — №2. — C. 14-29. [Belaya ZY, Rozhinskaya LY. Vitamin $\mathrm{D}$ in the treatment of osteoporosis: its role in the combination with antiosteoporotic therapy, non-skeletal effects. Effektivnaya farmakoterapiya. 2013;38(2):14-29. (In Russ.)]

136. Geusens PP, Lems WF. Fracture prevention in postmenopausal women with osteoporosis by an annual infusion of zoledronic acid. Ned Tijdschr Geneeskd. 2007;151(26):1445-1448.

137. Lyles KW, Colon-Emeric CS, Magaziner JS, et al. Zoledronic acid and clinical fractures and mortality after hip fracture. N Engl J Med. 2007;357(18):1799-1809. doi: https://doi.org/10.1056/NEJMoa074941 
138. Cummings SR, Lui LY, Eastell R, Allen IE. Association Between Drug Treatments for Patients With Osteoporosis and Overal Mortality Rates: A Meta-analysis. JAMA Intern Med. 2019. doi: https://doi.org/10.1001/jamainternmed.2019.2779

139. Bliuc D, Tran T, van Geel T, et al. Mortality risk reduction differs according to bisphosphonate class: a 15-year observational study. Osteoporos Int. 2019;30(4):817-828. doi: https://doi.org/10.1007/s00198-018-4806-0

140. Lee $\mathrm{P}, \mathrm{Ng}$ C, Slattery A, et al. Preadmission Bisphosphonate and Mortality in Critically III Patients. J Clin Endocrinol Metab. 2016;101(5):1945-1953. doi: https://doi.org/10.1210/jc.2015-3467

141. Bergman J, Nordstrom A, Hommel A, et al Bisphosphonates and mortality: confounding in observational studies? Osteoporos Int. 2019;30(10):1973-1982. doi: https://doi.org/10.1007/s00198-019-05097-1

142. Barzilai N, Crandall JP, Kritchevsky SB, Espeland MA. Metformin as a Tool to Target Aging. Cell Metab. 2016;23(6):1060-1065. doi: https://doi.org/10.1016/j.cmet.2016.05.011

143. Anisimov VN, Berstein LM, Egormin PA, et al. Metformin slows down aging and extends life span of female SHR mice. Cell Cycle. 2008;7(17):2769-2773. doi: https://doi.org/10.4161/cc.7.17.6625

144. Landman GW, Kleefstra N, van Hateren KJ, et al. Metformin associated with lower cancer mortality in type 2 diabetes: ZODIAC-16. Diabetes Care. 2010;33(2):322-326. doi: https://doi.org/10.2337/dc09-1380

145. Lee MS, Hsu CC, Wahlqvist ML, et al. Type 2 diabetes increases and metformin reduces total, colorectal, liver and pancreatic cancer incidences in Taiwanese: a representative population prospective cohort study of 800,000 individuals. BMC Cancer. 2011;11:20. doi: https://doi.org/10.1186/1471-2407-11-20

146. Tseng $\mathrm{CH}$. Diabetes, metformin use, and colon cancer: a populationbased cohort study in Taiwan. Eur J Endocrinol. 2012;167(3):409-416. doi: https://doi.org/10.1530/EJE-12-0369

147. Tosca L, Rame C, Chabrolle C, et al. Metformin decreases IGF1-induced cell proliferation and protein synthesis through AMP-activated protein kinase in cultured bovine granulosa cells. Reproduction. 2010;139(2):409-418. doi: https://doi.org/10.1530/REP-09-0351

148. Karnevi E, Said K, Andersson R, Rosendahl AH. Metformin-mediated growth inhibition involves suppression of the IGF-I receptor signalling pathway in human pancreatic cancer cells. BMC Cancer. 2013;13:235. doi: https://doi.org/10.1186/1471-2407-13-235
149. Zi FM, He JS, LiY, et al. Metformin displays anti-myeloma activity and synergistic effect with dexamethasone in in vitro and in vivo xenograft models. Cancer Lett. 2015;356(2 Pt B):443-453. doi: https://doi.org/10.1016/j.canlet.2014.09.050

150. Niehr F, von Euw E, Attar N, et al. Combination therapy with vemurafenib (PLX4032/RG7204) and metformin in melanoma cell lines with distinct driver mutations. J Trans/ Med. 2011:9:76. doi: https://doi.org/10.1186/1479-5876-9-76

151. Colquhoun AJ, Venier NA, Vandersluis AD, et al. Metformin enhances the antiproliferative and apoptotic effect of bicalutamide in prostate cancer. Prostate Cancer Prostatic Dis. 2012;15(4):346-352. doi: https://doi.org/10.1038/pcan.2012.16

152. Li L, Han R, Xiao H, et al. Metformin sensitizes EGFR-TKI-resistant human lung cancer cells in vitro and in vivo through inhibition of IL-6 signaling and EMT reversal. Clin Cancer Res. 2014;20(10):2714-2726. doi: https://doi.org/10.1158/1078-0432.CCR-13-2613

153. Blandino $G$, Valerio $M$, Cioce $M$, et al. Metformin elicits anticancer effects through the sequential modulation of DICER and C-MYC. Nat Commun. 2012;3:865. doi: https://doi.org/10.1038/ncomms1859

154. XuY, Lu S. Metformin inhibits esophagus cancer proliferation through upregulation of USP7. Cell Physiol Biochem. 2013;32(5):1178-1186. doi: https://doi.org/10.1159/000354517

155. Algire C, Amrein L, Zakikhani M, et al. Metformin blocks the stimulative effect of a high-energy diet on colon carcinoma growth in vivo and is associated with reduced expression of fatty acid synthase. Endocr Relat Cancer. 2010;17(2):351-360. doi: https://doi.org/10.1677/erc-09-0252

156. Gandini S, Puntoni M, Heckman-Stoddard BM, et al. Metformin and Cancer Risk and Mortality: A Systematic Review and Meta-analysis Taking into Account Biases and Confounders. Cancer Prev Res (Phila). 2014;7(9):867-885. doi: https://doi.org/10.1158/1940-6207.capr-13-0424

157. Effect of intensive blood-glucose control with metformin on complications in overweight patients with type 2 diabetes (UKPDS 34). Lancet. 1998;352(9131):854-865 doi: https://doi.org/10.1016/s0140-6736(98)07037-8

158. Lautrup S, Caponio D, Cheung H-H, et al. Studying Werner syndrome to elucidate mechanisms and therapeutics of human aging and age-related diseases. Biogerontology. 2019;20(3):255-269. doi: https://doi.org/10.1007/s10522-019-09798-2

\section{ИНФОРМАЦИЯ ОБ АВТОРАХ [AUTHORS INFO]}

*Голоунина Ольга Олеговна, студент [Olga O. Golounina, Student, Medical faculty]; адрес: Россия, 119991, Москва, ул. Трубецкая, д. 8, стр. 2 [address: 8-2 Trubetskaya street, 119991 Moscow, Russia]; ORCID: https://orcid.org/0000-0003-2320-1051; eLibrary SPIN: 7793-2123; e-mail: olga.golounina@mail.ru

Фадеев Валентин Викторович, д.м.н., профессор, член-корр. PAH [Valentin V. Fadeyev, MD, PhD, Professor]; email: walfad@mail.ru; ORCID: http://orcid.org/0000-0002-3026-6315; eLibrary SPIN: 6825-8417

Белая Жанна Евгеньевна, д.М.H., профессор [Zhanna E. Belaya, MD, PhD, Professor]; email: jannabelaya@gmail.com; ORCID: http://orcid.org/0000-0002-6674-6441; eLibrary SPIN: 4746-7173

\section{ЦИТИРОВАТЬ:}

Голоунина О.О., Фадеев В.В., Белая Ж.Е. Наследственные синдромы с признаками преждевременного старения // Остеопороз и остеопатии. — 2019. - Т. 22. — №3 - C.4-18. doi: https://doi.org/10.14341/osteo12331

\section{TO CITE THIS ARTICLE:}

Golounina OO, Fadeyev VV, Belaya ZE. Hereditary syndromes with signs of premature aging. Osteoporosis and bone diseases. 2019;22(3):4-18. doi: https://doi.org/10.14341/osteo12331 